This item was submitted to Loughborough's Research Repository by the author.

Items in Figshare are protected by copyright, with all rights reserved, unless otherwise indicated.

\title{
Modulating the photocatalytic activity of TiO2 (P25) with lanthanum and graphene oxide
}

PLEASE CITE THE PUBLISHED VERSION

https://doi.org/10.1016/j.jphotochem.2018.11.048

\section{PUBLISHER}

(C) Elsevier

\section{VERSION}

AM (Accepted Manuscript)

\section{PUBLISHER STATEMENT}

This paper was accepted for publication in the journal Journal of Photochemistry and Photobiology A: Chemistry and the definitive published version is available at https://doi.org/10.1016/j.jphotochem.2018.11.048.

\section{LICENCE}

CC BY-NC-ND 4.0

\section{REPOSITORY RECORD}

Coelho, Leticya Lais, Dachamir Hotza, Arthur Senra Estrella, Suelen M. de Amorim, Gianluca Li-Puma, and Regina F.P.M. Moreira. 2019. "Modulating the Photocatalytic Activity of Tio2 (P25) with Lanthanum and Graphene Oxide”. figshare. https://hdl.handle.net/2134/36545. 


\section{Accepted Manuscript}

Title: Modulating the photocatalytic activity of $\mathrm{TiO}_{2}(\mathrm{P} 25)$ with lanthanum and graphene oxide

Authors: Leticya Lais Coelho, Dachamir Hotza, Arthur Senra Estrella, Suélen Maria de Amorim, Gianluca Li Puma, Regina de Fatima Peralta Muniz Moreira

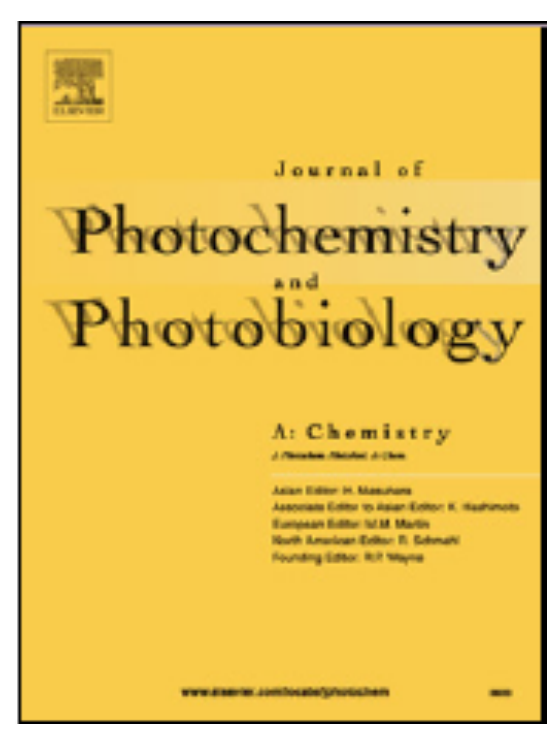

PII: S1010-6030(18)30821-9

DOI: $\quad$ https://doi.org/10.1016/j.jphotochem.2018.11.048

Reference: $\quad$ JPC 11620

To appear in: Journal of Photochemistry and Photobiology A: Chemistry

Received date: $\quad 11$ June 2018

Revised date: $\quad 29$ November 2018

Accepted date: $\quad 30$ November 2018

Please cite this article as: Lais Coelho L, Hotza D, Senra Estrella A, de Amorim SM, Li Puma G, de Fatima Peralta Muniz Moreira R, Modulating the photocatalytic activity of $\mathrm{TiO}_{2}$ (P25) with lanthanum and graphene oxide, Journal of Photochemistry and amp; Photobiology, A: Chemistry (2018), https://doi.org/10.1016/j.jphotochem.2018.11.048

This is a PDF file of an unedited manuscript that has been accepted for publication. As a service to our customers we are providing this early version of the manuscript. The manuscript will undergo copyediting, typesetting, and review of the resulting proof before it is published in its final form. Please note that during the production process errors may be discovered which could affect the content, and all legal disclaimers that apply to the journal pertain. 
Modulating the photocatalytic activity of $\mathrm{TiO}_{2}$ (P25) with lanthanum and graphene oxide

Leticya Lais Coelho ${ }^{1}$, Dachamir Hotza ${ }^{1}$, Arthur Senra Estrella ${ }^{1}$, Suélen Maria de Amorim

Gianluca Li Puma², Regina de Fatima Peralta Muniz Moreira ${ }^{1, *}$

${ }^{1}$ Laboratory of Energy and Environmental Process, Department of Che ICa andFood

Engineering, Federal University of Santa Catarina, Campus Universitário rindade, $\$ 8040$ 900,

Florianópolis, SC, Brazil

${ }^{2}$ Environmental Nanocatalysis \& Photoreaction Ex minee ng, Department of Chemical Engineering, Loughborough University, LE11 3TU vughburough, United Kingdom

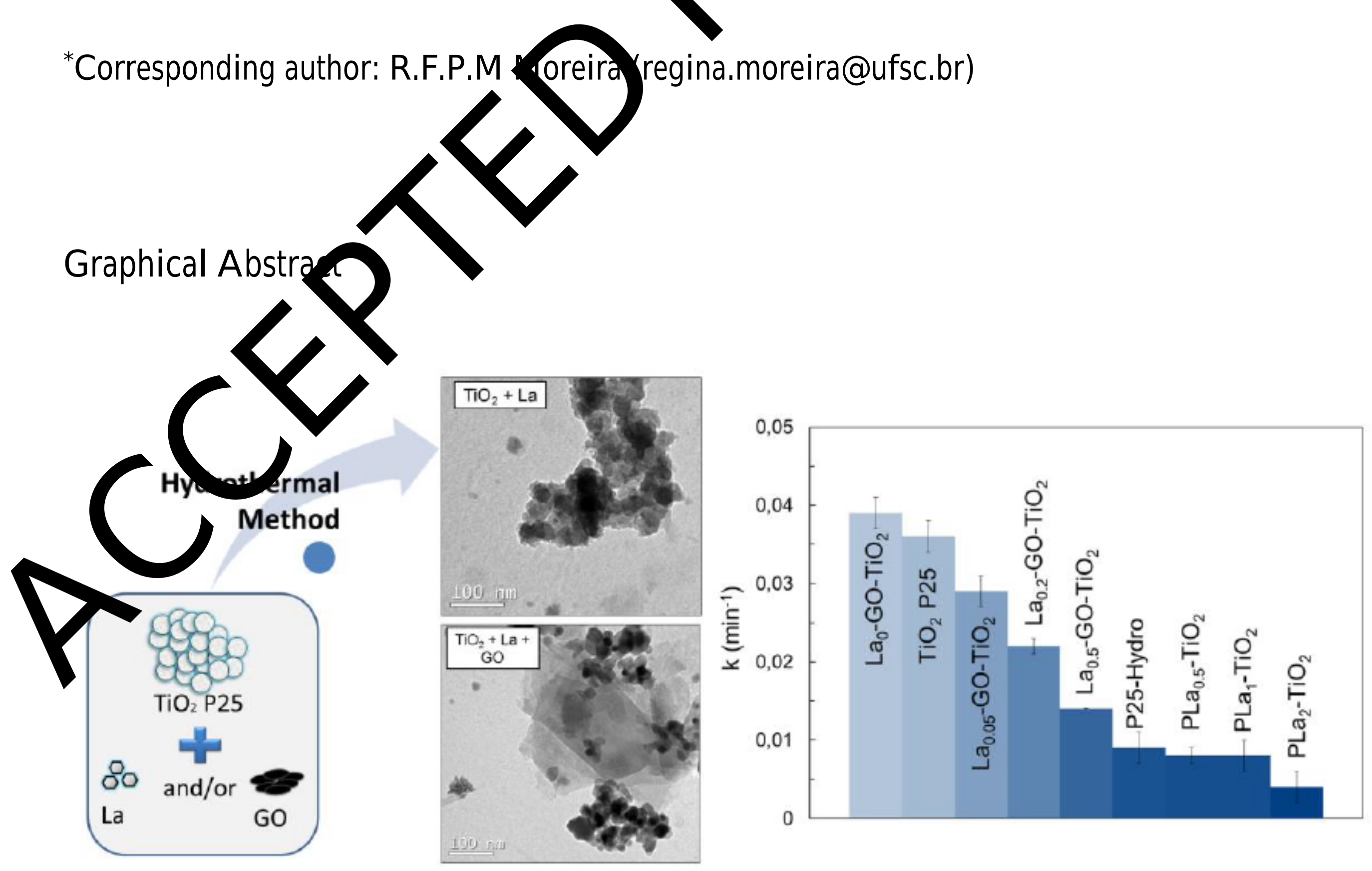




\section{Highlights}

- The photocatalytic activity modulation concept was demonstrated.

- La-doped $\mathrm{TiO}_{2}$ may be used as a tool for suppressing the photoactivity.

- La inhibited particle agglomeration and increased the thermal stability of anatase

- The addition of GO reduced charge recombination and improved adsorption s ility

\section{Abstract}

The modulation and tuning of the photocatalytic activity com ercial titanium dioxide $\left(\mathrm{TiO}_{2}\right)$ P25 nanoparticles is demonstrated through xporation of lanthanum (La) and/or graphene oxide (GO). These composite pass which could have applications in commercial products, were prepared by a wo-step hydrothermal method from the corresponding precursors. The effor of $\$ 0.05-2 \mathrm{~mol} \%)$ and GO $(5 \mathrm{~m} \%)$ content on the crystal structure, morph $10 \mathrm{~g}$ nd hotocatalytic activity of $\mathrm{TiO}_{2}$ was investigated by XRS, SEM, EDS, TE UV Drole DRS, point of zero charge, photoluminescence and the decolorizatio of nethylene blue. Lanthanum modified the recombination rate of the photogenera electron-hole charges on $\mathrm{TiO}_{2}$ by inducing an increase in the structural defeats, which resulted in a significant suppression, up to $90 \%$, of the photocatalytic ackity the UVA light region. In contrast, the addition of GO enhanced the notocatalytic activity of $\mathrm{TiO}_{2}$. Materials with tuned intermediate photoactivity within the entire range from high to very low were prepared by dosing appropriate amounts of La and GO species. The strategy of combining La and GO represents a useful and simple method for tuning or for suppressing the photocatalytic activity of $\mathrm{TiO}_{2}$ under UVA light irradiation in materials and consumer products using $\mathrm{TiO}_{2}$. 
Keywords: titanium dioxide; graphene oxide; rare earths; lanthanides.

\section{Introduction}

The semiconductor titanium dioxide $\left(\mathrm{TiO}_{2}\right)$ has been widely investigated in recent decades as an effective photocatalyst for the decomposition of organic molecules 1 . When $\mathrm{TiO}_{2}$ absorbs light with energy higher than its bandgap, primarily in the of the electromagnetic spectrum, electron-hole pairs are created within re ulk the solid. These photogenerated charges, after migration to the surf ce, cap react with adsorbed $\mathrm{O}_{2}$ and $\mathrm{H}_{2} \mathrm{O}$, yielding highly powerful radical oxidizi spg ies (ROS), which in turn can decompose organic molecules into $\mathrm{CO}_{2}$ and $\mathrm{H}_{2}$ [2].

Extensive research efforts have been directed wanhancing the photocatalytic activity of $\mathrm{TiO}_{2}$; however, for some application tbe ativity of $\mathrm{TiO}_{2}$ should be partially or completely suppressed. The photocentiven of $\mathrm{TiO}_{2}$ should be suppressed, for instance, when it is used in the fo the polymers and regular paints, since this may induce a loss of their optic and manical properties when exposed to light irradiation. In sunscreen formans curaining $\mathrm{TiO}_{2}$ or other semiconductor materials, the photogenerated Sares may cause damage to DNA and human health $[3,4]$. In the establisher ap ication as a white pigment for paints, plastics and other products, the catyticticty of titanium dioxide reduces the long-term durability of the polymeric manrial [5].

On the other hand, $\mathrm{TiO}_{2}$ has also been incorporated into photocatalytically active paints to impart self-cleaning and self-disinfecting properties to the painted surfaces, as well as photoactive thin film surfaces for the decontamination of air contaminants. In these cases, the photocatalytic activity of the paint or film should be partially preserved 
without affecting the durability and quality of the painted film or promoting the formation of toxic compounds resulting from the decomposition of organic additives used in the paint products [6,7]. As a consequence, the properties of such films or paints, particularly when used in an indoor environment, would need to be optimized in order to minimize the risk of the emission of harmful substances.

The total suppression of the photocatalytic activity of $\mathrm{TiO}_{2}$ can be achieve coating with $\mathrm{Al}_{2} \mathrm{O}_{3}$ [5] or with polydimethylsiloxane films [4]. However, it has een demonstrated that the protective $\mathrm{Al}(\mathrm{OH})_{3}$ layer on $\mathrm{TiO}_{2}$ nanoparticles $\mathrm{n}$ darmaged and leached when in contact with some ions frequently present i surface water and swimming pool water, exposing the $\mathrm{TiO}_{2}$ nanoparticles. [8]

The photocatalytic activity of $\mathrm{TiO}_{2}$, particularly no vis le light irradiation, can be altered by ion doping, anatase-rutile phase coexist n neterojunction formation. Among then, ion doping has been proved as an efi-1errt approach [9-12].

However, few studies have modulating and/or suppressing the photocatalytic activity of $\mathrm{TiO}_{2}$ strategies generally applied to reduce or tune the photoactivity of semicond Cormats include metal doping or physical coating of the photocatalysts $[4,13$

Hybridphofatalysts with the addition of transition metals or non-metals and, more regent) rarths and nanocarbon compounds are a promising alternative apprac to $n$ dulating the photoactivity, either increasing or inhibiting it by altering the ele ron properties of the semiconductor [15-20].

With non-metal doping, the replacement of the $\mathrm{O}$ atoms of the $\mathrm{TiO}_{2}$ by the added component (e.g., nitrogen, sulfur or phosphorous) may result in the hybridization of $2 p$ orbitals from the non-metal to the $2 p$ orbital of the semiconductor, leading to the formation of new energy levels above the valence band of the semiconductor and 
narrowing of the bandgap, consequently increasing the photoactivity of $\mathrm{TiO}_{2}$ under visible light [21]. Among the non-metals, graphene can increase the photoactivity of photocatalysts due to, among other factors, the high mobility of charges within the graphene structure and through the formation of Ti-O-C bonds [22-27]. In contrast, the metal atoms act as a mediator between the reacting species and the semiconductor through a mechanism involving the migration of the excited electrons of the semiconduretor towards the energy levels of the co-catalyst [17].

Rare-earth metal doping can also introduce structural defects in th cr stals fo the semiconductor, such as oxygen vacancies that can act as electron wit drawal stes, which may increase the separation efficiency of photogenerated berty-gap pairs [17]. Although $\mathrm{Ln}^{3+}$ ions cannot replace $\mathrm{Ti}$ atoms in the crystan ne la ice of $\mathrm{TiO}_{2}$, due to the difference in the ionic radius, it should be possible soromitute $\mathrm{Ln}^{3+}$ of the lanthanide oxide with $\mathrm{Ti}$, forming Ti-O-Ln bonds [28],As a re soquence, the anatase to rutile phase transition is inhibited in $\mathrm{Ln}^{3+}$-doperaten the photocatalyst is exposed to temperatures higher than $600^{\circ}$

In this study, we dmonstre the modulation of the photivity of $\mathrm{TiO}_{2}$ (P25) through the synthesis or hotocalytic composites incorporating lanthanum and graphene oxide. The compo wito were fully characterized and their photocatalytic activity evaluated through aradation of the methylene blue dye, to elucidate the modulation me man ob lained by the simultaneous presence of GO and La species. Materials with tun in ermediate photoactivity within the entire range from high to very low were prepared by dosing appropriate amounts of La and GO.

\section{Experimental}


The reagents used in this study were of analytical grade. The aqueous solutions were prepared using distilled water. $\mathrm{TiO}_{2}$ P25 (Evonik) and lanthanum nitrate hexahydrate $\mathrm{La}\left(\mathrm{NO}_{3}\right)_{3} \cdot 6 \mathrm{H}_{2} \mathrm{O}$ (Vetec) were used as received. Graphene (Graphene Nanopowder 1-5 nm, Skyspring Nanomaterials, USA) was first oxidized by treatment with ozone for $16 \mathrm{~h}$ to produce graphene oxide (GO) [31]. Methylene blue (MB) $\mathrm{C}_{16} \mathrm{H}_{18} \mathrm{C}_{1} \mathrm{~N}_{3} \mathrm{~S}_{3} . \mathrm{H}_{2} \mathrm{O}$ (Lafan) was selected for the evaluation of the photocatalytic actiurty of the materials. Nitrogen gas $\left(\mathrm{N}_{2}\right)$ was used during the heat treatment the photocatalysts.

\subsection{Synthesis}

Lanthanum and/or graphene oxide were incorporato into $\mathrm{TiO}_{2} \mathrm{P} 25$ nanoparticles in percentages of $0.05 \%$ to $2.0 \% \mathrm{~mol} / \mathrm{mol}$ for $\mathrm{La}: \mathrm{TiO}$ an $\% \mathrm{~m} / \mathrm{m}$ for GO: $\mathrm{TiO}_{2}$.

The photocatalysts were synthesized ov se two-step hydrothermal method. Initially, for the ternary composites, 2.4. P25 and the desired mass of lanthanum nitrate were suspended in $70 \mathrm{~m}$ previously prepared ethanol/water solution (1:2). Separately, $0.12 \mathrm{~g}$ of GO $30 \mathrm{ml}$ of the same solution. Both suspensions were sonicated in an a sontator (Unique, model UCS 1650) at room temperature for $2 \mathrm{~h}$. The suspens $\mathrm{w}$ were then mixed together and sonicated for an additional $2 \mathrm{~h}$ to ensure comple digpersion and homogeneity. The binary composite photocatalysts were prepared in a dmilar manner with $2.4 \mathrm{~g}$ of $\mathrm{TiO}_{2} \mathrm{P} 25$ and the desired amount of La or GO. Tha colis were added together in $100 \mathrm{ml}$ of the ethanol/water solution and sonicated for $4 \mathrm{~h}$. The resulting suspension was then placed in a Teflon autoclave and maintained at $120^{\circ} \mathrm{C}$ for $3 \mathrm{~h}$, allowed to cool to room temperature under atmospheric air and dried in an oven for at least $15 \mathrm{~h}$ at $60^{\circ} \mathrm{C}$. The subsequent solid mass was then ground manually using a pestle and mortar, resulting in a fine powder. Subsequently, each solid was 
submitted to a further thermal treatment by heating from ambient temperature to $600{ }^{\circ} \mathrm{C}$ at a heating rate of $10^{\circ} \mathrm{C} \mathrm{min}^{-1}$ and maintaining the final temperature for $3 \mathrm{~h}$. The thermal treatments were carried out in air except for the samples containing GO which were heated under a $\mathrm{N}_{2}$ atmosphere. A pure $\mathrm{TiO}_{2}$ control sample $\left(\mathrm{TiO}_{2} \mathrm{P} 25-\mathrm{Hydro}\right)$ was also prepared using the two-step synthesis method. Details of all photocatalysts used in this study are summarized in Table 1.

Table 1 - Details of photocatalysts investigated in this study.

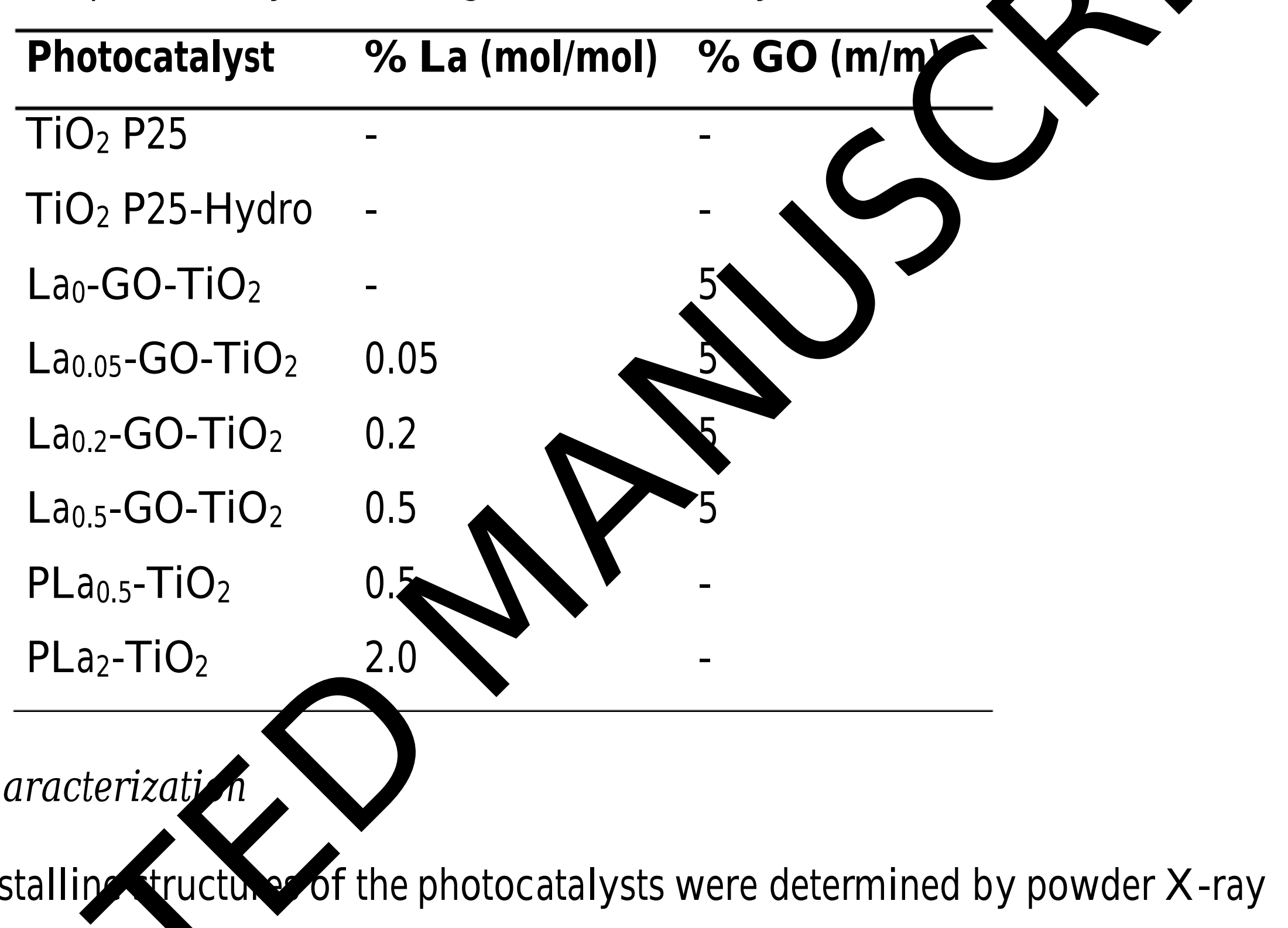
diffraction (XRL Tle analysis was performed at room temperature, using a Philips $\mathrm{X}$ 'Pert X-ray a actometer equipped with $\mathrm{Cu} \mathrm{K \alpha}$ at $40 \mathrm{kV}$ and $30 \mathrm{~mA}$, geometry $\theta-2 \theta$ and $\lambda=15.056$ with a scanning speed of $0.05^{\circ}$ step/s in the $2 \theta$ range of 00 to $80^{\circ}$. The res lts we quantified using the Rietveld refinement software. The surface area was reasured by the BET method in an automatic adsorptometer (Autosorb-1C Quantachrome, USA). For this analysis the samples were previously degassed at $200{ }^{\circ} \mathrm{C}$ for $4 \mathrm{~h}$ under vacuum.

Transmittance electron microscopy (TEM) and scanning electron microscopy (SEM) images were obtained with JEM-1011 and JEOL JSM-6390LV microscopes, 
respectively. The HRTEM patterns were obtained with a JEOL, JEM 2100 microscope equipped with a field emission electron gun and operating at $200 \mathrm{kV}$. For this procedure, selected samples were dispersed in an alcohol suspension and a drop of the suspension was placed over a grid with holey-carbon film.

Energy-dispersive X-ray spectroscopy (EDS) was carried with the instrument coupled to the SEM microscope. Diffuse reflectance spectra (DRS) were obtained with a Tensor 27 spectrophotometer (Bruker) from 200 to $700 \mathrm{~nm}$. Photoluminescenct L) analysis was carried out using a Varian Eclipse spectrophotometer at ro n mpenture with an excitation wavelength of $320 \mathrm{~nm}$, and a scanning rate of $0.5 \mathrm{~nm} \mathrm{~s}^{-1}$ the range of 360 to $500 \mathrm{~nm}$. The point of zero charge $\left(\mathrm{pH}_{\mathrm{pzc}}\right)$ of the phato ary ts was determined on a Stabino-Nanoflex analyzer.

Electron paramagnetic resonance (EPR) meas remos were recorded by a Bruker ESP 300E spectrometer (Bruker Instruments, In Pals00K. The EPR parameter values were obtained by treating and simularentarimental spectra using the Windows software programs Win-EPR and Fonia and the Weak Pitch Bruker pattern.

\subsection{Photocatalytic A a ty}

The photo at ytic activity of the materials was evaluated in a reaction vessel (13 cm diamarer ) ted with a magnetic stirring bar and a UV-A lamp ( $\lambda=365 \mathrm{~nm} ; 8 \mathrm{~W}$; F8T5 Blactig bly Ushio) positioned horizontally, $8 \mathrm{~cm}$ above the bottom of the reaction

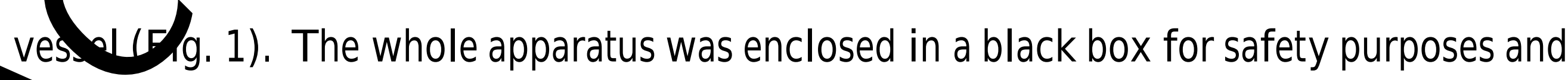
Lo eliminate external light interferences. In a typical photocatalytic reaction, $0.125 \mathrm{~g}$ of the photocatalyst was suspended in $250 \mathrm{~mL}$ of $\mathrm{MB}$ solution $\left(10 \mathrm{mg} \mathrm{L}^{-1}\right.$ ) inside a circular vessel and mixed under strong magnetic stirring in the dark for $15 \mathrm{~min}$. The reaction was initiated when the light was turned on. At regular time intervals a $3 \mathrm{~mL}$ aliquot of the 
suspension was collected and centrifuged or filtered through a $0.22 \mu \mathrm{m}$ PVDF membrane (Millipore) to separate the solids. The MB concentration was measured using a $\mathrm{HACH}$ spectrophotometer (model DR 5000) at the wavelength of maximum absorbance ( $\lambda=665$ $\mathrm{nm})$. The kinetics of MB degradation in the absence of a catalyst and under dark conditions was also investigated. All experiments were performed at pH 5.5.

Figure 1 - Experimental apparatus used for the evaluation of the photocatalytic actiuty of the samples.

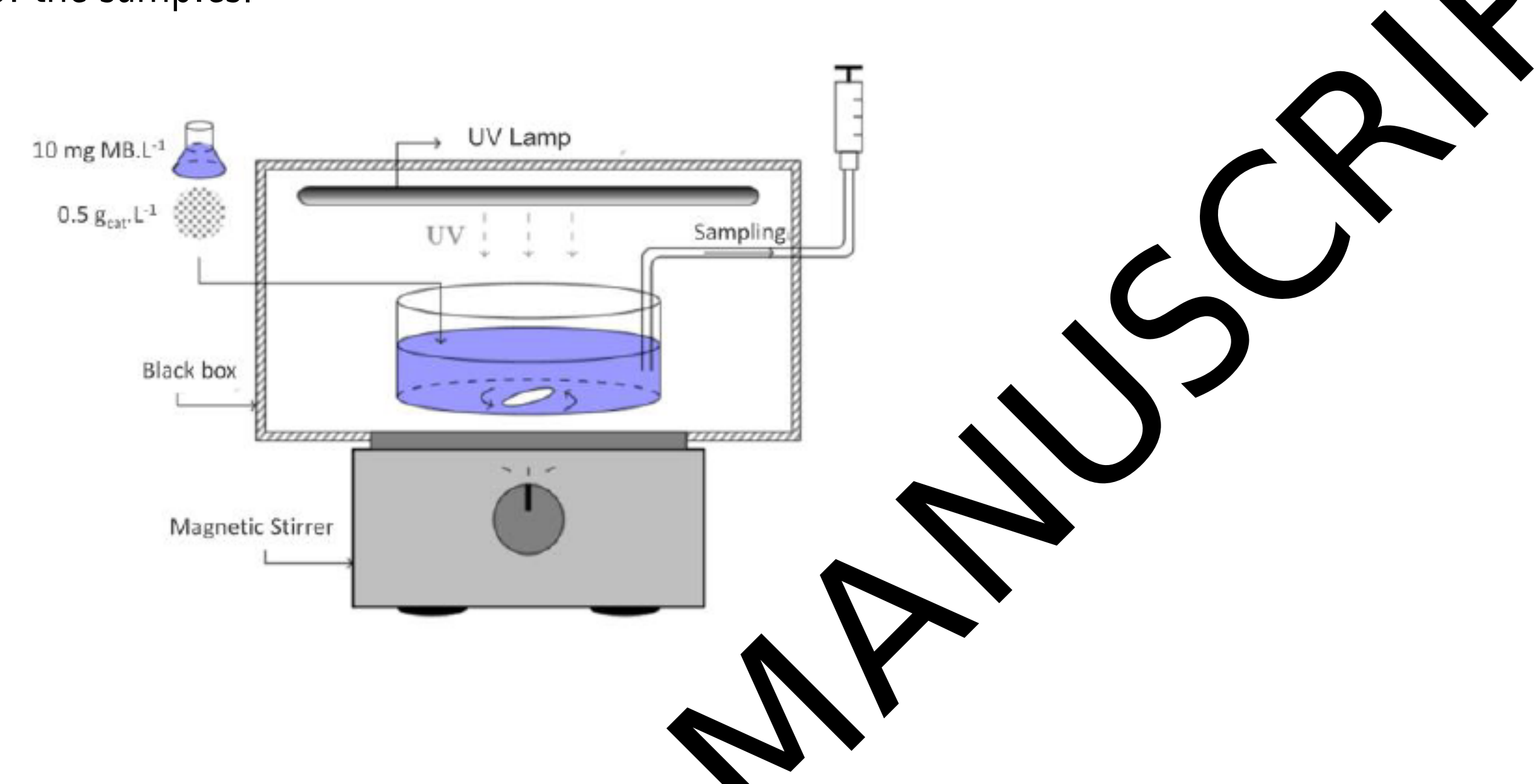

\section{Results and Discussion}

3.1 Characterization of the ph octocalysts

Anatase a ran tile were the only crystalline phases identified in the solid samples by XRD, w ch may result from the low amounts of La and GO used. The quantitative analysi (Table 2 ) clearly showed that the thermal treatment led to a partial anatase to ru ile phose transition for the $\mathrm{La}_{0}-\mathrm{GO}-\mathrm{TiO}_{2}$ composite sample and the P25-Hydro Pocatalyst, with the percentage of rutile increasing from $14.2 \%$ in the P25 sample to $27.4 \%$ and $23.1 \%$, respectively, in these photocatalysts. On the other hand, the stabilization of the anatase phase by La doping was observed even at low La concentrations and in the presence of graphene oxide. The amounts of rutile and anatase 
in the $\mathrm{La}_{0.05}-\mathrm{GO}-\mathrm{TiO}_{2}$ and $\mathrm{La}_{0.2}-\mathrm{GO}-\mathrm{TiO}_{2}$ samples were approximately equal to the values obtained for the commercial $\mathrm{TiO}_{2} \mathrm{P} 25$.

Because of this phase stabilization, the BET surface areas of La-doped $\mathrm{TiO}_{2}$ samples are nearly the same, as well as the $\mathrm{N}_{2}$ adsorption/desorption isotherms at $77 \mathrm{~K}$ (Figure S1). An increase in the surface area of the photocatalyst containing GO in relation to P25-Hydro was observed, which was attributed to the high surface area of the grapkene $\left(710 \mathrm{~m}^{2} \mathrm{~g}^{-1}\right)$ and larger open structure. The BET surface area of ternary com site materials increased at higher lanthanum content because of the progres ve stabizizing effect of lanthanum on the $\mathrm{TiO}_{2}-\mathrm{GO}$ structure, which probably inhibi s the aggromeration of the particles.

Table 2 - Quantitative XRD analysis and BET for d photocatalysts.

\begin{tabular}{|c|c|c|c|}
\hline Photocatalyst & Rutile (\% $\mathrm{m} / \mathrm{m})$ & An: ab & $\begin{array}{l}\text { BET surface area } \\
\left(\mathrm{m}^{2} \mathrm{~g}^{-1}\right)\end{array}$ \\
\hline $\mathrm{TiO}_{2} \mathrm{P} 25$ & 14.2 & & 50.0 \\
\hline $\mathrm{TiO}_{2} \mathrm{P} 25-\mathrm{HydrO}$ & 23.1 & & 23.8 \\
\hline $\mathrm{La}_{0}-\mathrm{GO}-\mathrm{TiO}_{2}$ & 21 & 72.6 & 46.7 \\
\hline $\mathrm{La}_{0.05}-\mathrm{GO}-\mathrm{TiO}_{2}$ & & 85.2 & 54.8 \\
\hline $\mathrm{La}_{0.2}-\mathrm{GC}$ & & 86.4 & 56.7 \\
\hline & & - & 70.2 \\
\hline & 16.9 & 83.1 & 47.3 \\
\hline & 16.9 & 83.1 & 50.0 \\
\hline \multirow{3}{*}{\multicolumn{4}{|c|}{ his characteristic was common to all photocatalysts and structural changes were no }} \\
\hline & & & \\
\hline & & & \\
\hline \multicolumn{4}{|c|}{ lentified in any of the samples. The presence of $L a$ and $G O$ on the surface of the } \\
\hline
\end{tabular}




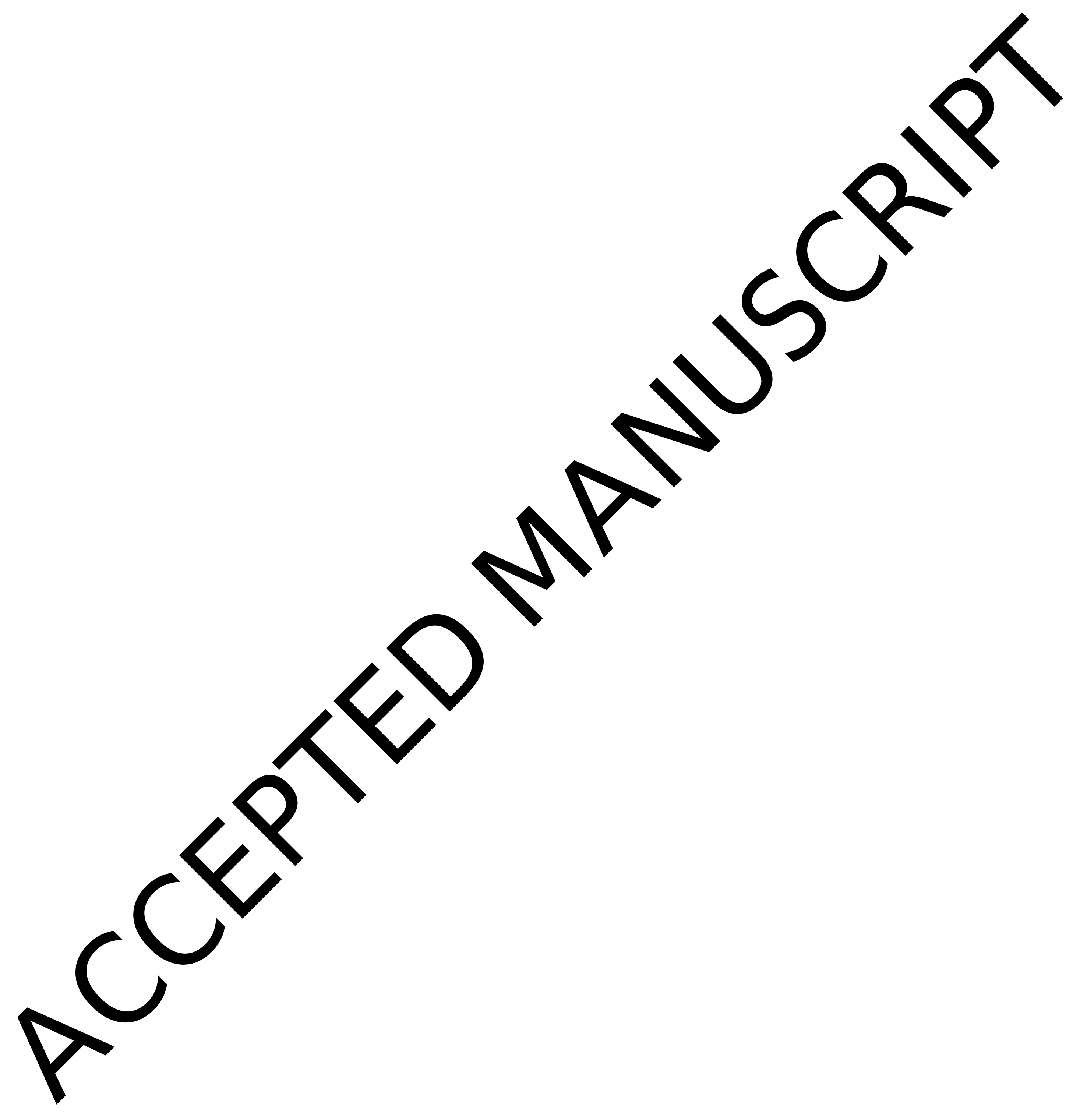


Figure 2 - SEM images of (a) $\mathrm{TiO}_{2} \mathrm{P} 25-\mathrm{Hydro}$, (b) $\mathrm{La}_{0}-\mathrm{GO}-\mathrm{TiO}_{2}$ and (c) $\mathrm{PLa}_{2}-\mathrm{TiO}_{2}$.
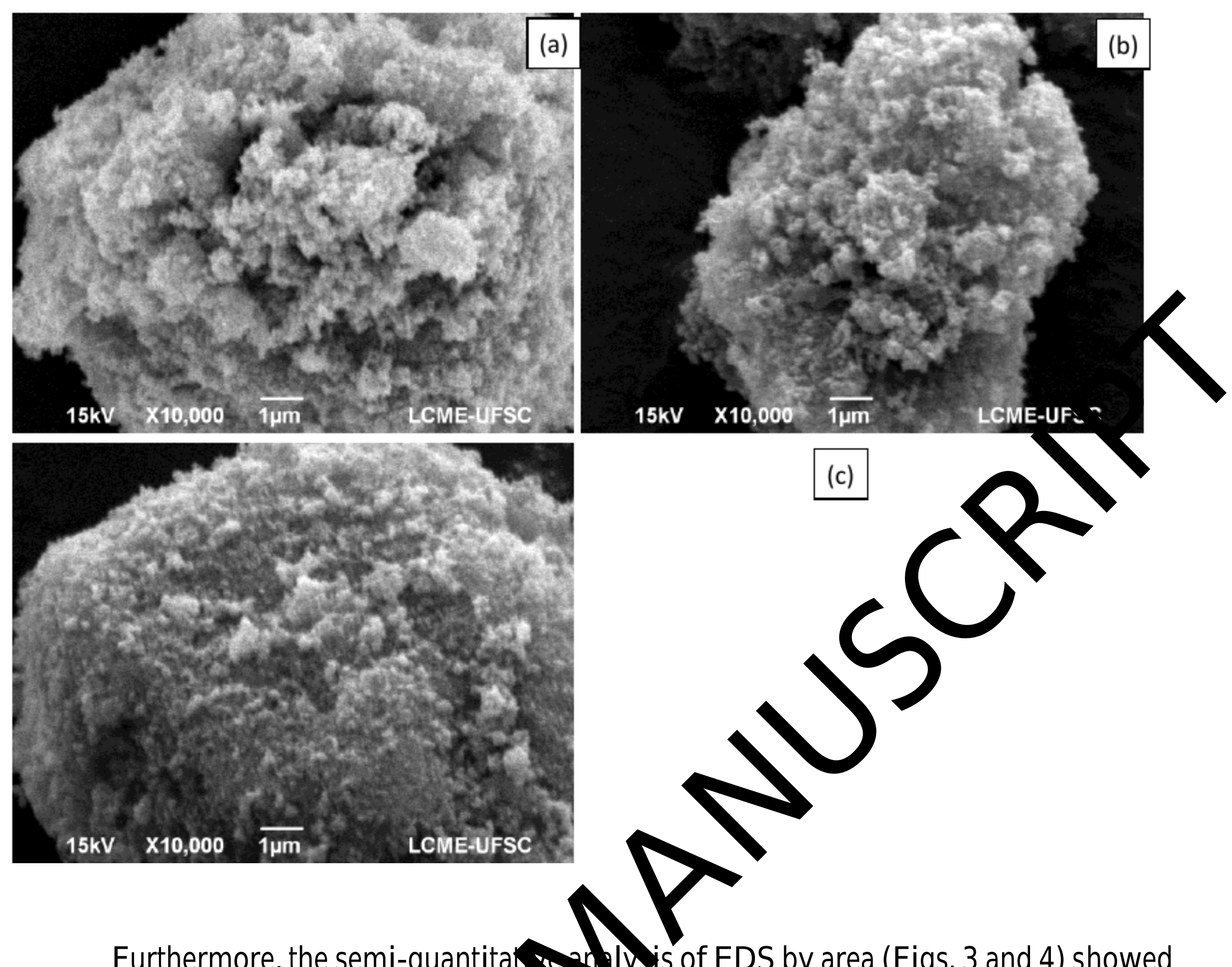

Furthermore, the semi-quantita 1 is of EDS by area (Figs. 3 and 4) showed the presence of carbon originatip g Tru GO and lanthanum on the surface of the La 0 -GO$\mathrm{TiO}_{2}$, La0.5-GO-TiO 2 and $\mathrm{SL}_{2}-\mathrm{T}_{2}$ composites (Table 3). Small differences were observed in the resus, which as attributed to the nominal amounts of each compound added during the procedure. This verified the good degree of dispersion of the graphenexia andianthanum in the photocatalysts. 
Figure 3 - SEM images and EDS areas for (a) $\mathrm{La} \mathrm{a}_{0}-\mathrm{GO}-\mathrm{TiO}_{2}$, (b) $\mathrm{La}_{0.5}-\mathrm{GO}-\mathrm{TiO}_{2}$ and (c) $\mathrm{PLa}_{2}-\mathrm{TiO}_{2}$.
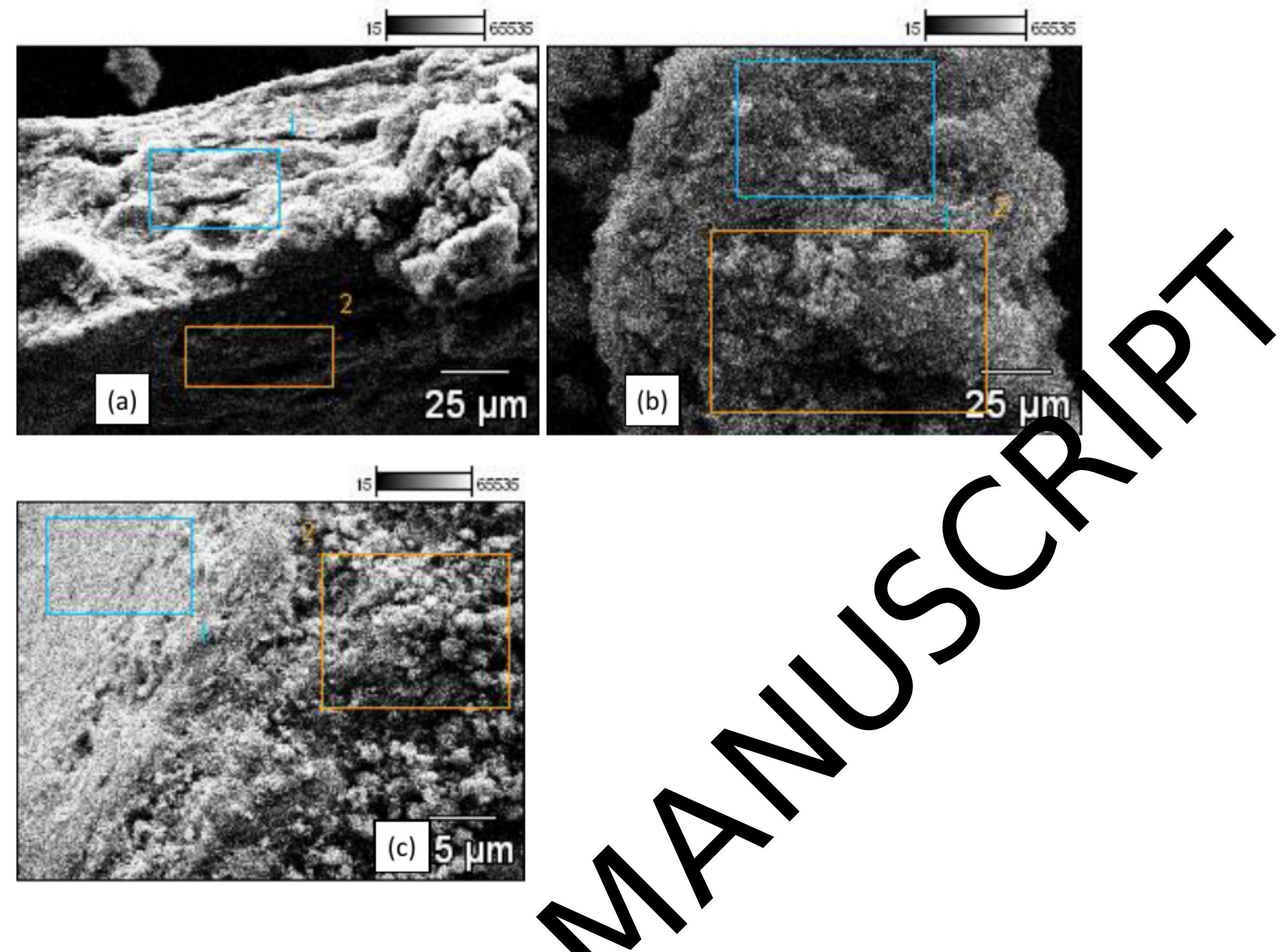

Table 3 - Semi-quantitative analy enf EDSresults by area*.

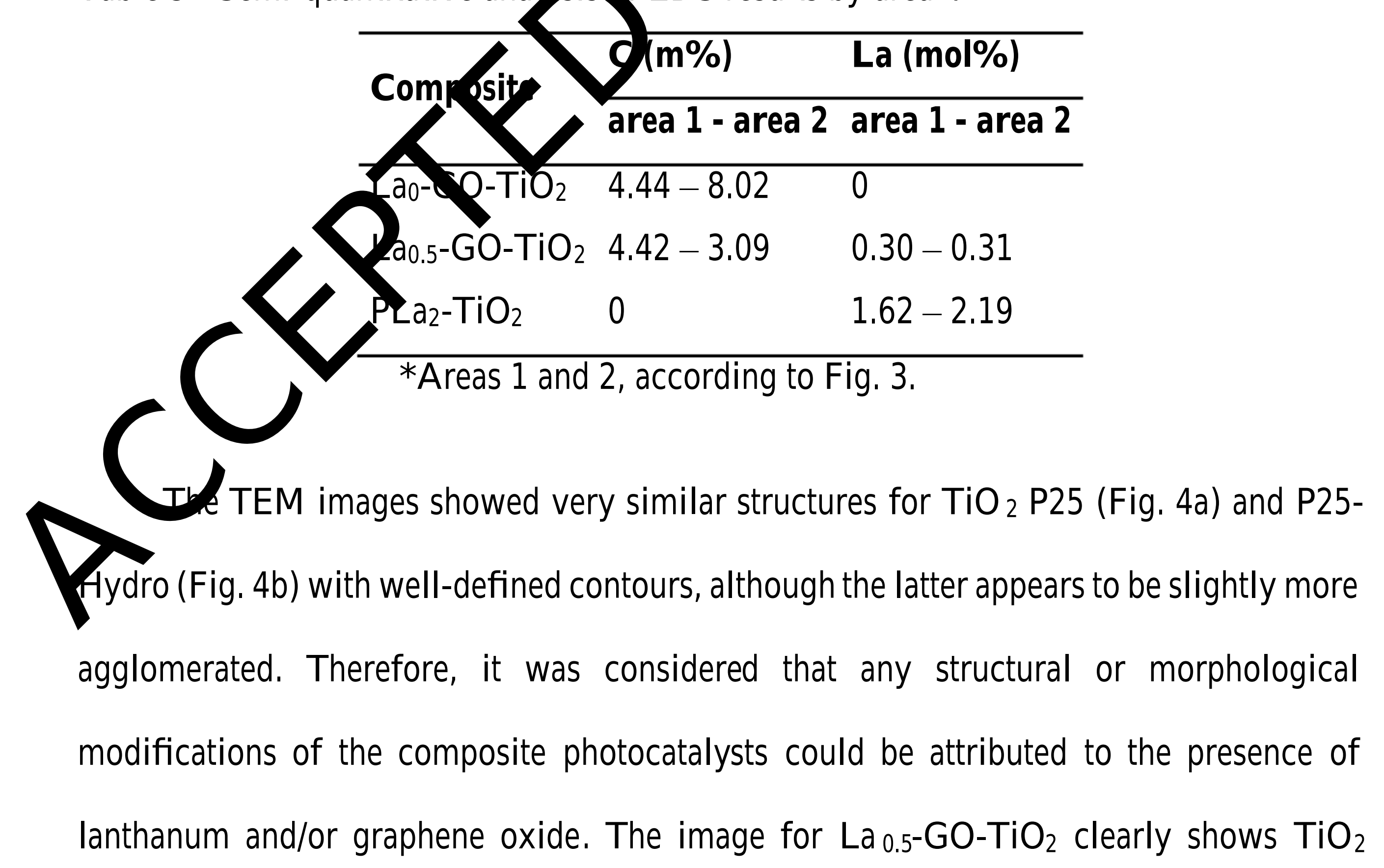


particles adhered to the graphene sheets (Fig. 4c). The small particles of $\mathrm{La}_{2} \mathrm{O}_{3}$ were difficult to visualize by TEM due to their morphological similarity with $\mathrm{TiO}_{2}$. However, even in the visual absence of lanthanum hydroxide needles, the presence of lanthanum was indicated by the surface modifications observed on the samples with La, which were characterized by a loss of well-defined contours, as shown in Fig. $4 \mathrm{~d}$ for $\mathrm{La}_{0.5}-\mathrm{GO}-\mathrm{TiO}_{2}$ and Fig. 4e for $\mathrm{PLa}_{2}-\mathrm{TiO}_{2}$. No regions were identified on the images where the presuce of titanium, lanthanum and graphene was visible. This demonstrates a low deg of homogeneity of the samples, as well as a possible lack of affinity betweer he larbom and lanthanum compounds.

Lanthanum atoms are unable to enter the crystalline natw o $\mathrm{TiO}_{2}$ due to their large atomic radius [32] and, as a result, will remain or th surfo ge the photocatalyst. The surface coating of $\mathrm{TiO}_{2}$ with lanthanum oxide co ranow esponsible for the formation of recombination sites (as confirmed by the pho ormescence analysis, Fig. 7), with a consequent decrease in the photocat actity. Despite the good dispersion of graphene oxide and lanthany agested by the EDS results (Table 3), $\mathrm{TiO}_{2}$ agglomerates without surace morications were also found in the photocatalytic composites.

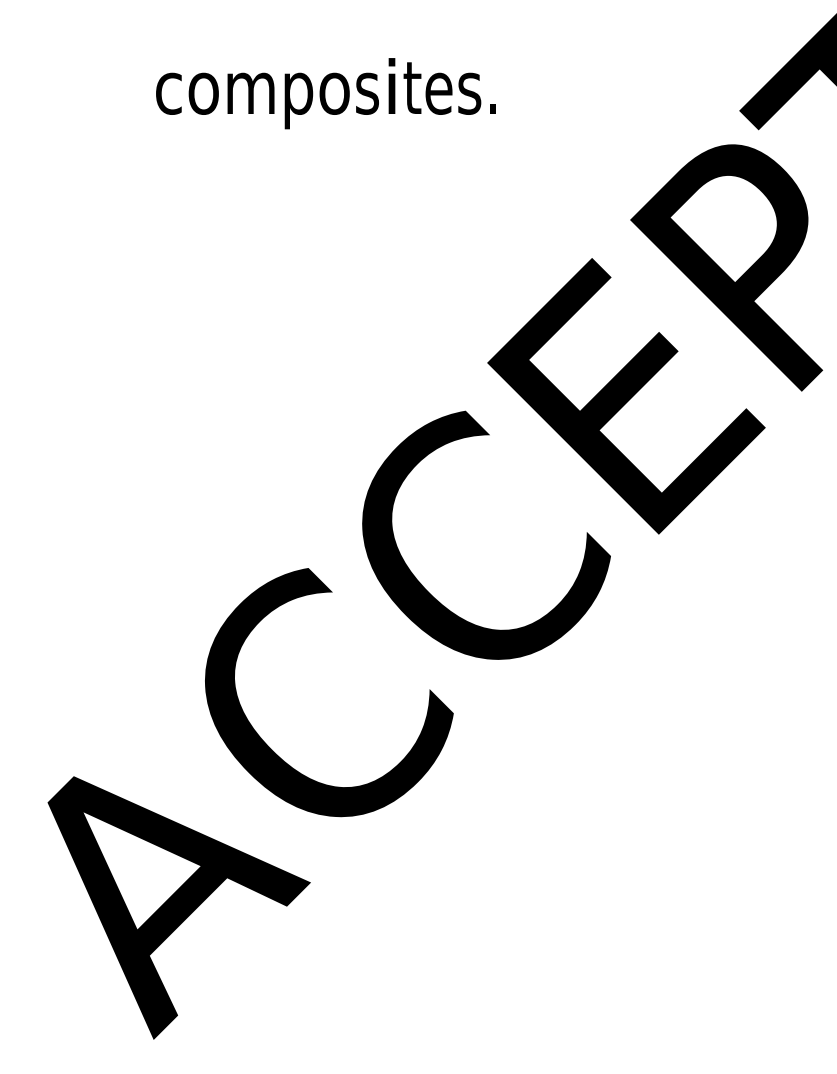


Figure 4 - TEM images for P25 (a), P25-Hydro (b), La 0.5-GO-TiO 2 (c-d) and $\mathrm{PLa}_{2}-\mathrm{TiO}_{2}$ (e).
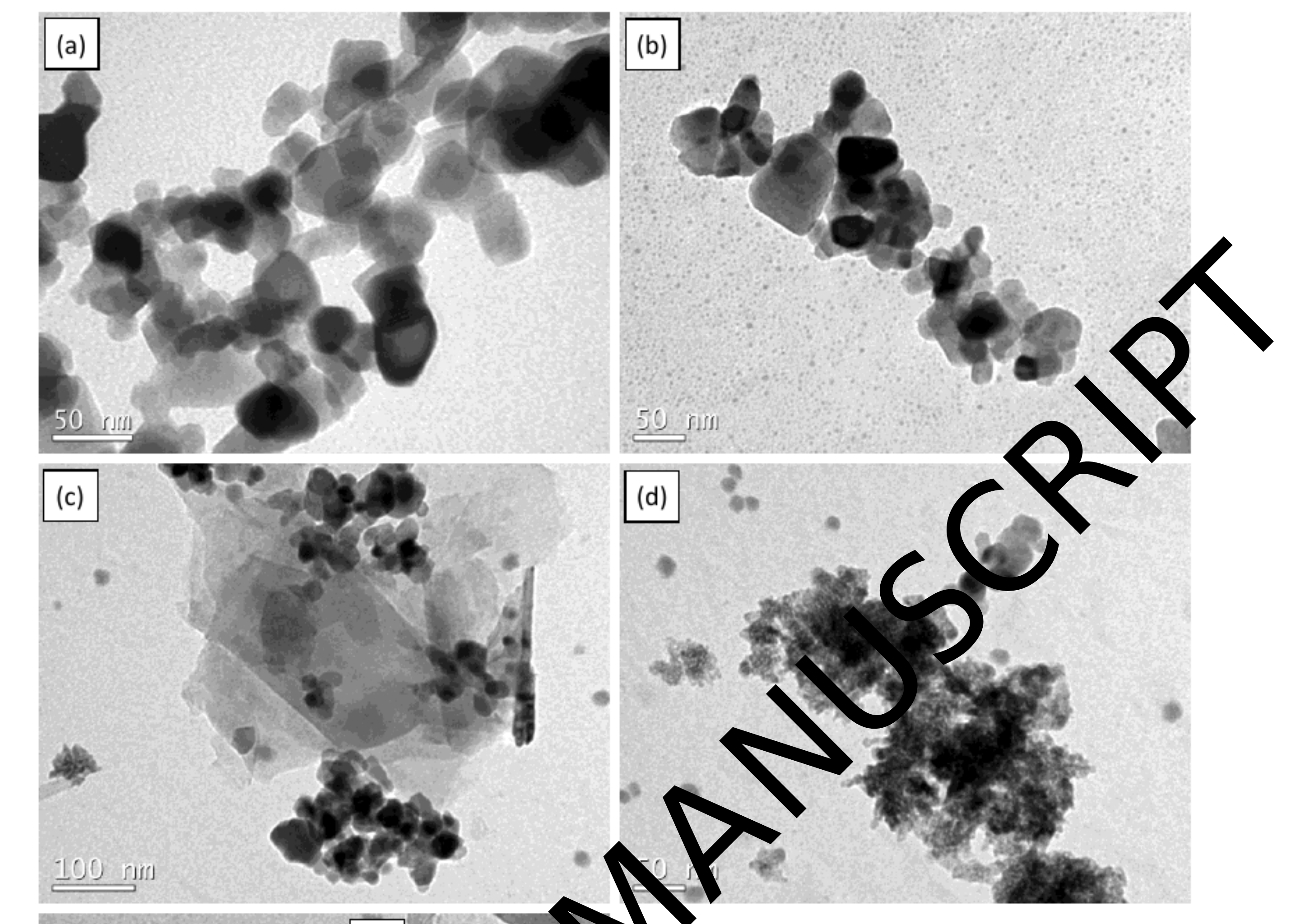
$\mathrm{TiO}_{2}$ ) do not appear to be expanded, but showed waviness (see Fig. 5c), which could be ascribed to possible electric stress originating from the La ion doping [33].
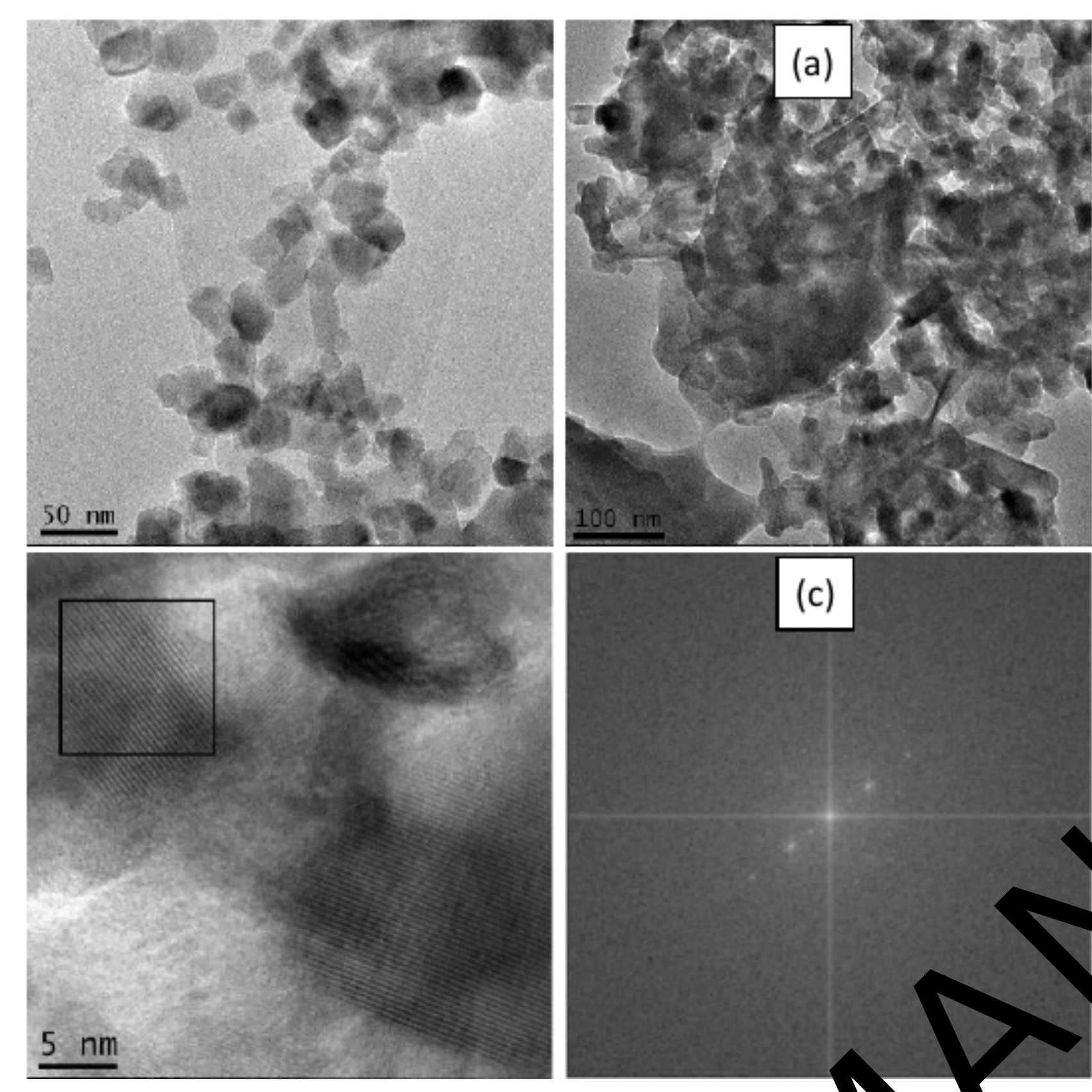

(b)

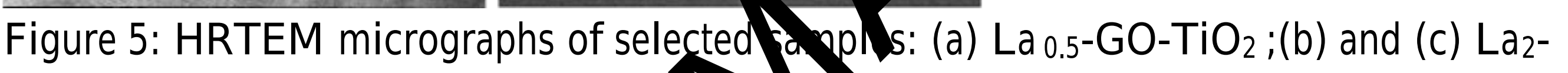
$\mathrm{TiO}_{2} ;$ (d) SAED pattern of $\mathrm{La}_{2}-\mathrm{TiO}_{2}$.

\section{(c)}
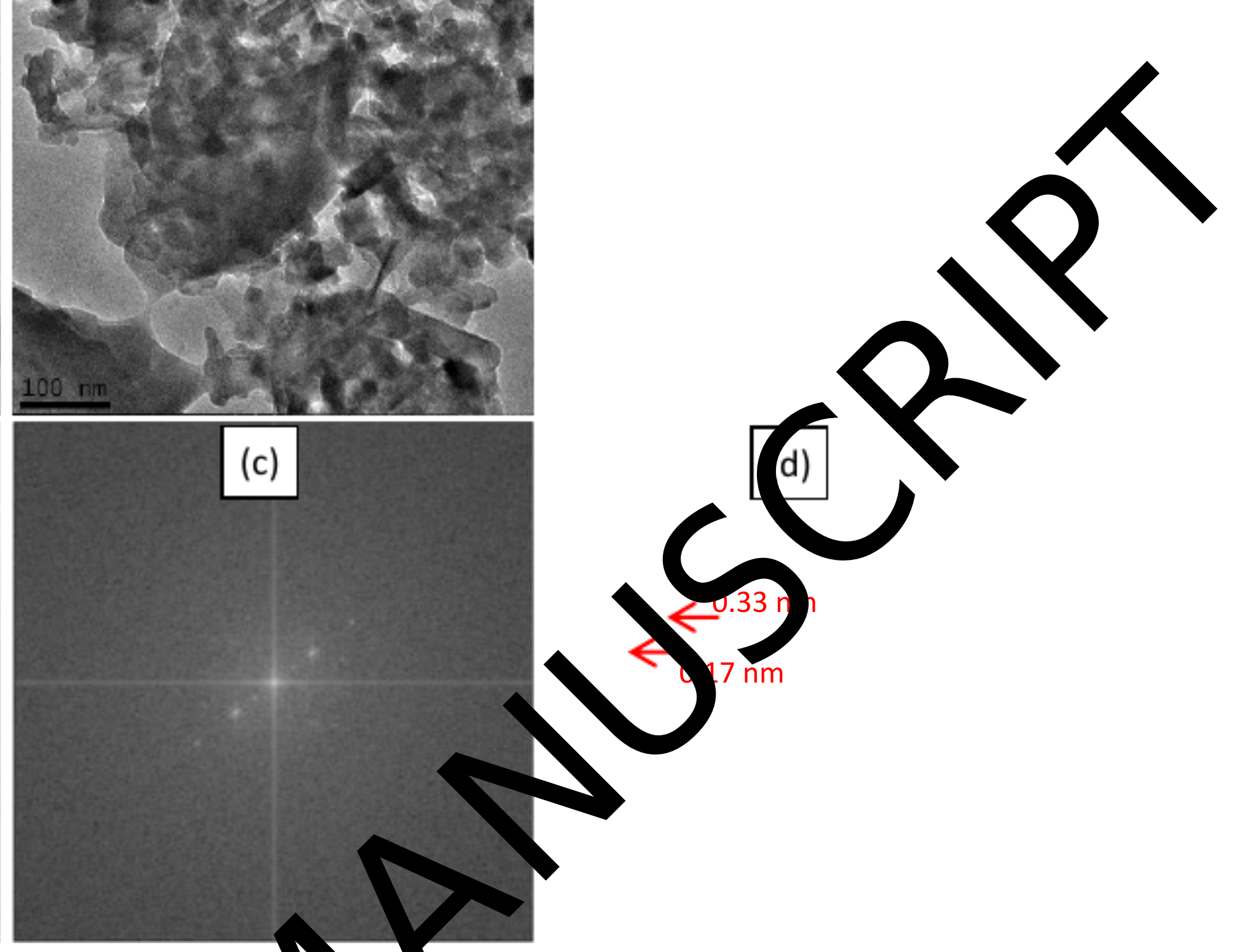

$\gtrless_{7 \mathrm{~nm}}$

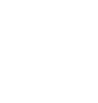
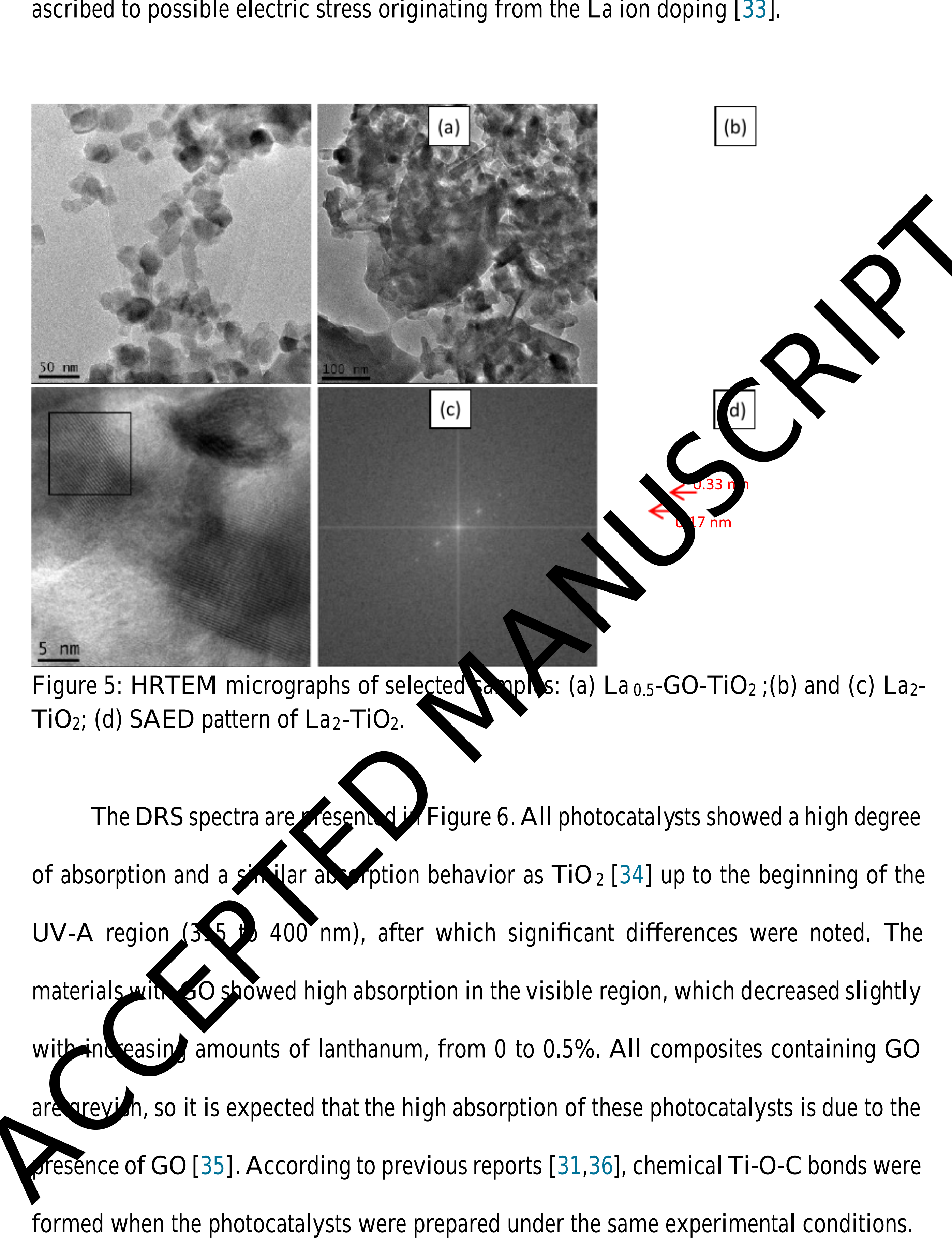

Figure 6 - DRS spectra (a) and Kubelka-Munk function $\left(\mathrm{F}_{K M} h v^{1 / 2}\right)$ (b) for different photocatalysts. 


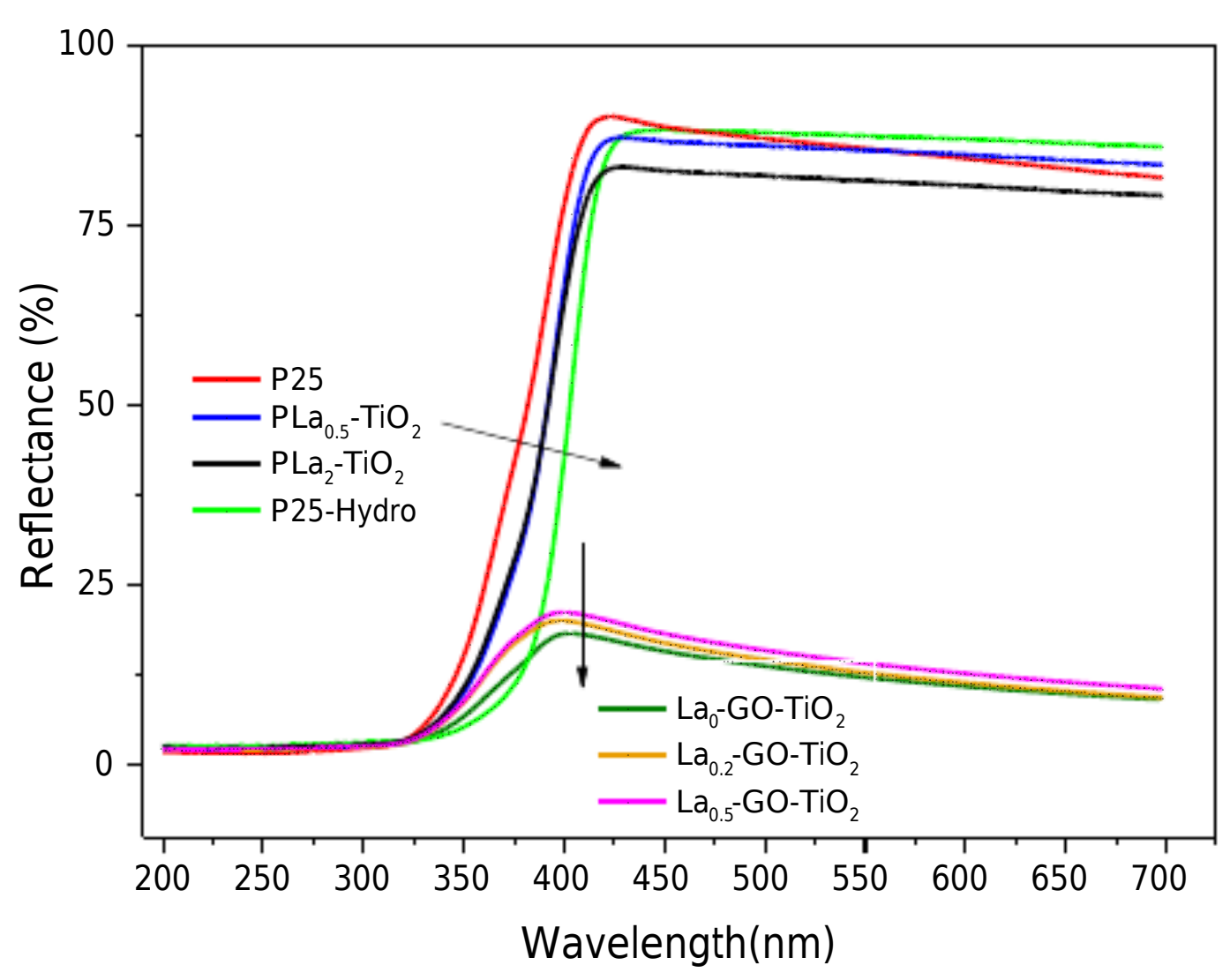

(a)

(b)

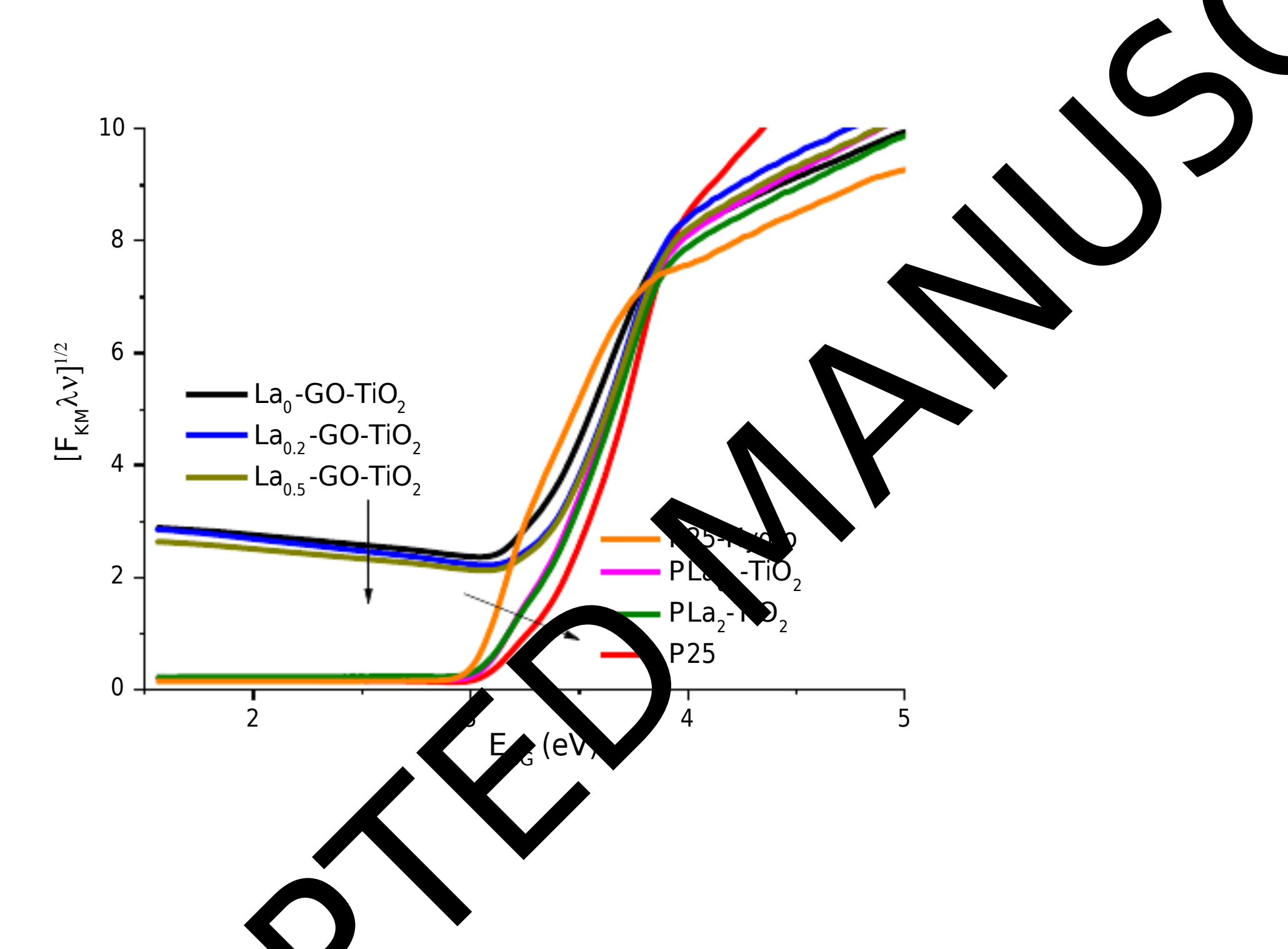

co nposite, rrowed low absorption in the visible range, similar to $\mathrm{TiO}_{2} \mathrm{P} 25$, although

In Contrat he $\mathrm{TiO}_{2}$ with $\mathrm{La}$, which does not change the final color of the (1) (1)

$\mathrm{PL}_{1}-\mathrm{TrO}_{2}$ had a slightly higher absorption in the visible region. The reflectance data were

used to estimate the bandgap energy (Table 3) from the Kubelka-Munk function $\left(F_{K M}(R D)\right)$ (Equation 1).

$$
\frac{()^{2}}{2 R D} \frac{}{s}
$$


where $S$ is the scattering factor, is the molar extinction coefficient, $h v$ is the photon energy and $R D$ is the diffuse reflectance.

As seen in Table 4, $\mathrm{TiO}_{2}$ P25-Hydro and $\mathrm{La}_{0}-\mathrm{GO}-\mathrm{TiO}_{2}$ were the photocatalysts with the lowest bandgap values (2.85 and $3.05 \mathrm{eV})$. All other photocatalysts had bandgap energies varying between 3.16 and $3.36 \mathrm{eV}$ (Table 4). This narrowing of the bandgap is usually attributed to the formation of Ti-O-D bonds where D is a generic substance, sach as Ti-O-C when graphene oxide is added to the $\mathrm{TiO}_{2}$. This suggests that the additho of a metal and/or non-metal can play a fundamental role in the absorption vible right, resulting in a modification of the fundamental process of the formatic of photogenerated charge carriers, with bandgap narrowing of $\mathrm{TiO}_{2}$ obtained by sit ing valence band and/or by decreasing the conduction band [37]

Table 4 - Bandgap energy ( $\left.E_{B G}\right)$ for different pl po atalysts.

\begin{tabular}{ll} 
Photocatalyst & $\mathbf{F}_{\mathbf{B G}}(\mathbf{e V})$ \\
\hline $\mathrm{TiO}_{2} \mathrm{P} 25$ &
\end{tabular}

The prrotoluminescence results (Fig. 7) showed an increase in the emission intensity the region of 365 to $393 \mathrm{~nm}$, which was correlated to the La and/or GO content. This Jegion corresponded approximately to the bandgap energies of the photocatalysts [38]. The PL emission intensity of the samples with La were considerably higher, in comparison to the value for $\mathrm{P} 25-\mathrm{Hydro}$, as a result of an increase in the surface oxygen 
vacancies and structural defects acting as recombination centers. However, a La content in the range of 0.5 to $2.0 \%$ did not appear to change the intensity of the PL spectra.

Figure 7 - Photoluminescence results for different photocatalysts.

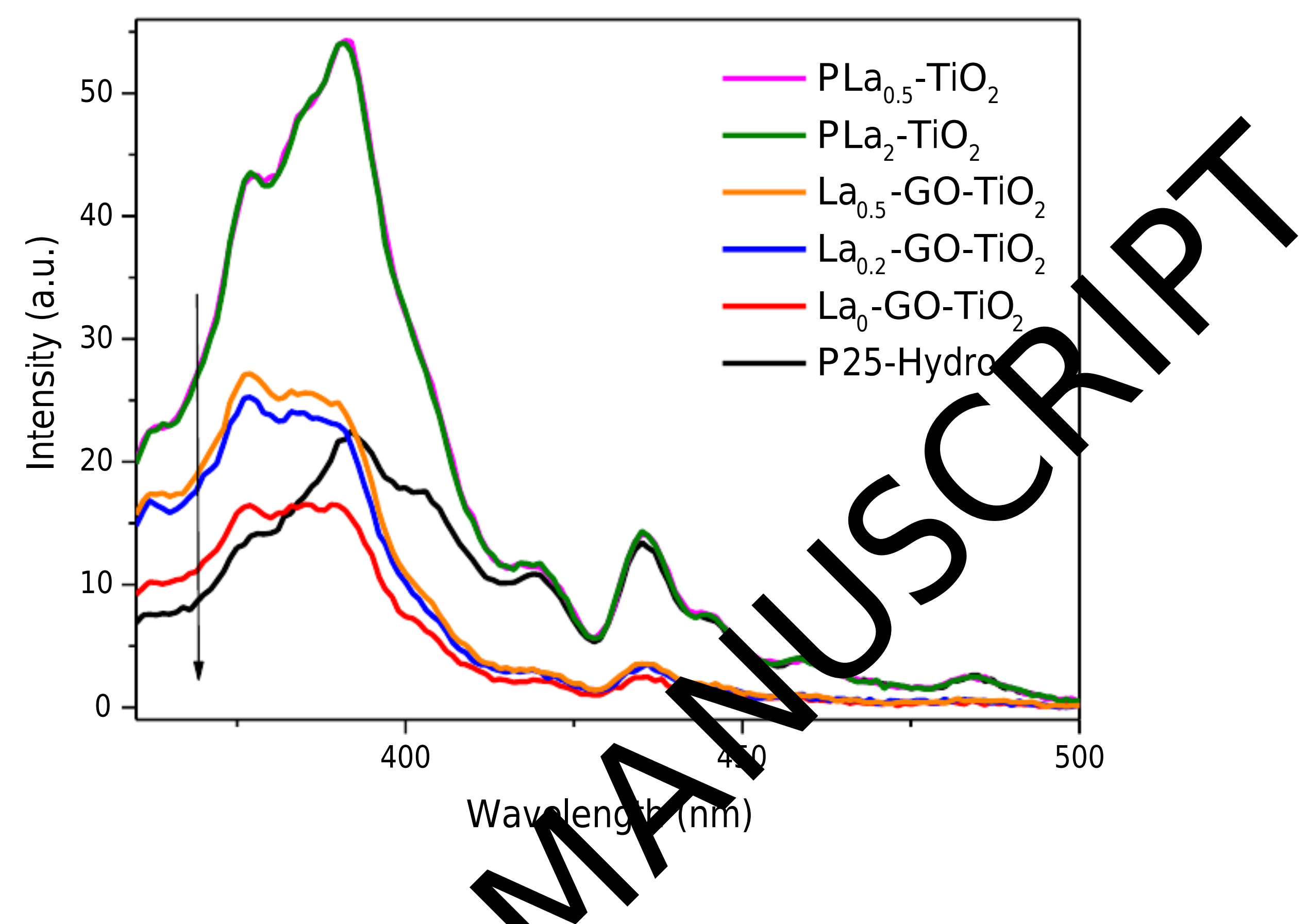

The introduction of GO in tharample with La resulted in a marked reduction in the PL emission intensity. This pho onenon is well known and attributed to the high electronic conductivit of GW which reduces the charge recombination. In the visible region, the terna $\quad$ mposites had the same profile as the samples with $\mathrm{GO}$, presenting almost neg enission. Since the samples with GO absorb considerably more radiatio in th visible region than the $\mathrm{P} 25$-Hydro sample, this low emission intensity is ind cativ of higher photocatalytic activity in the visible light region.

EPR spectroscopy was used to detect the generated paramagnetic species and thus identify various trap sites for photogenerated electrons and holes. The spectra of La $0.5^{-}$ GO-TiO, $\mathrm{La}_{0}-\mathrm{GO}-\mathrm{TiO}_{2}$ and $\mathrm{PLa}_{0.5}-\mathrm{TiO}_{2}$ exhibited similar lineshapes (Figure S2), and $\mathrm{La}_{0.5}-\mathrm{GO}-\mathrm{TiO}_{2}$ showed clearer spectrum than $\mathrm{La}_{0}-\mathrm{GO}-\mathrm{TiO}_{2}$ or $\mathrm{PLa}_{0.5}-\mathrm{TiO}_{2}$. The $g$-values 
found in this work are in the range reported in the literature and suggested that the as samples generated radicals such as $\mathrm{O}^{\circ-}, \mathrm{O}_{2}{ }^{--}, \mathrm{Ti}^{4+} \mathrm{O}_{3}{ }^{--}, \mathrm{Ti}^{4+} \mathrm{O}^{\circ-}$, and $\mathrm{Ti}^{4+} \mathrm{OH}^{--}$, as well as oxygen vacancies $\left(\mathrm{V}_{0}{ }^{\circ}\right)$. [39-41]

The signal corresponding to $\mathrm{g} \sim 2.03$ should be ascribed to oxygen-centered anion radical covalently bound to titanium atoms in the of $\mathrm{Ti}^{4+} \mathrm{O}^{2-} \mathrm{Ti}^{4+} \mathrm{O}^{\cdot-}$ species on surface produced by surface brindging oxygen atoms trapping photogenerated he as proposed by Hongquan et al. [42].. This oxygen-centered anion radical is know to be responsible for most of the primary oxidation processes [39, 42, 43] The signal at about $g \sim 1.96-1.98$ could indicates the formation of $\mathrm{Ti}^{3+}$ spectes surface sites, and the signal with $g \sim 2.002-2.003$ is due to the presence of oxy en varancies [39, 40, 44, 45]. The appearance of $\mathrm{Ti}^{3+}$ into $\mathrm{TiO}_{2}$ has been explainea tormation of cross-linked bond $\mathrm{Ti}^{4+}-\mathrm{O}-\mathrm{M}^{3+}$ ( $\mathrm{M}$ is a metal), which coex wits oxygen vacancies [43]. So, the formation of Ti-O-La bonds could expla the signals measured for lanthanum doped- $\mathrm{TiO}_{2}$ samples (Figure S2a and Fig re S2c) $[46,47]$.

\subsection{Photocatalytic ag}

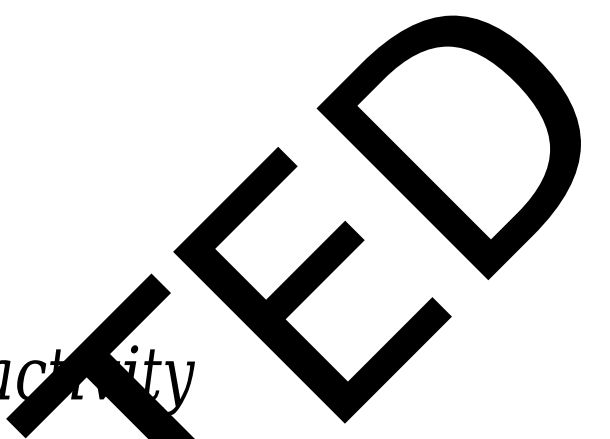

Table $5 \mathrm{~S}, \mathrm{~W}$, the amount of $\mathrm{MB}$ adsorbed over the photocatalysts in the dark prior to irrad con and the point of zero charge of the respective photocatalysts. The sampales with go presented a higher adsorption capacity as a result of their larger surface are In ontrast, the samples containing lanthanum strongly inhibited the adsorption of $\mathrm{B}$ since the addition of lanthanum caused an increase in the point of zero charge of the solids. The surface charge of the $\mathrm{La}-\mathrm{TiO}_{2}$ composite is positive at the $\mathrm{pH}$ used in the experiments, causing repulsion effects regarding the adsorption of the cationic dye (MB). This effect became stronger as the amount of lanthanum in the solid increased. 
Table 5 - Methylene blue adsorbed by the photocatalysts in the dark and the point of zero charge.

\begin{tabular}{lll}
\hline Photocatalyst & MB adsorbed (\%) & $\mathbf{p H}_{\mathbf{p z c}}$ \\
\hline $\mathrm{TiO}_{2} \mathrm{P} 25$ & 15.2 & 6.2 \\
$\mathrm{P} 25-\mathrm{Hydro}$ & 11.5 & 4.9 \\
$\mathrm{La}_{0}-\mathrm{GO}-\mathrm{TiO}_{2}$ & 32.0 & 5.3 \\
$\mathrm{La}_{0.05}-\mathrm{GO}-\mathrm{TiO}_{2}$ & 26.4 & 19.0 \\
$\mathrm{La}_{0.2}-\mathrm{GO}-\mathrm{TiO}_{2}$ & 19.7 \\
$\mathrm{La}_{0.5}-\mathrm{GO}-\mathrm{TiO}_{2}$ & 1.7 \\
$\mathrm{PLa}_{0.5}-\mathrm{TiO}_{2}$ & \\
$\mathrm{PLa}_{1}-\mathrm{TiO}_{2}$ & \\
$\mathrm{PLa}_{2}-\mathrm{TiO}_{2}$ &
\end{tabular}

With regard to the decor rization of MB under UV light irradiation, in the absence of a photocatalyst it sugnificant but in the presence of a photocatalyst the decolorization follod pudo-first-order kinetics (Fig. 8) for all materials investigated. 
Figure 8 - Kinetics of MB decolorization using different photocatalysts under UVA irradiation.

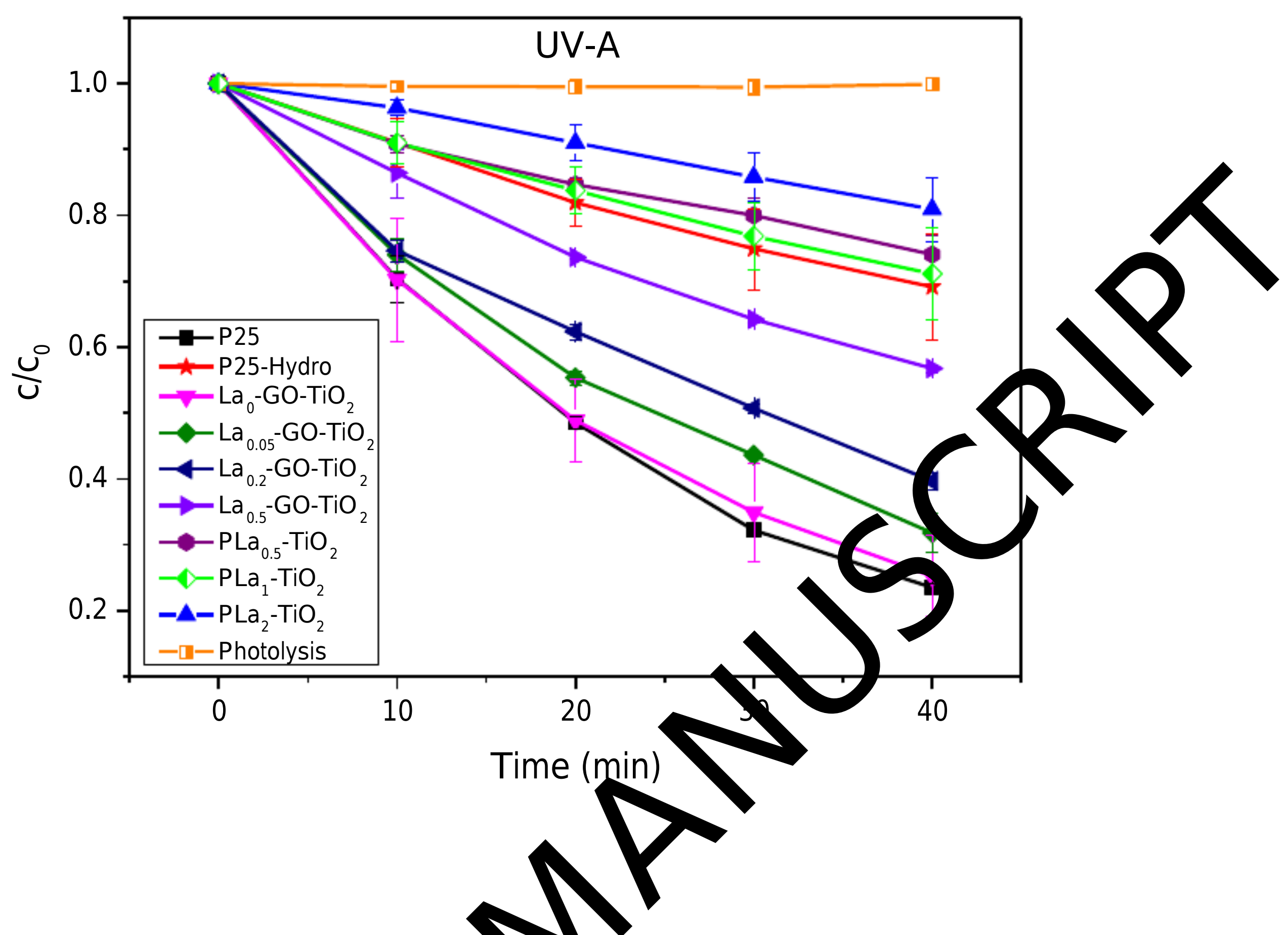

The reaction kinetics constants ob ined from fitting the experimental data to the material balance equation forth batch eactor combined with first-order reaction kinetics (Eq. 2) are shown in

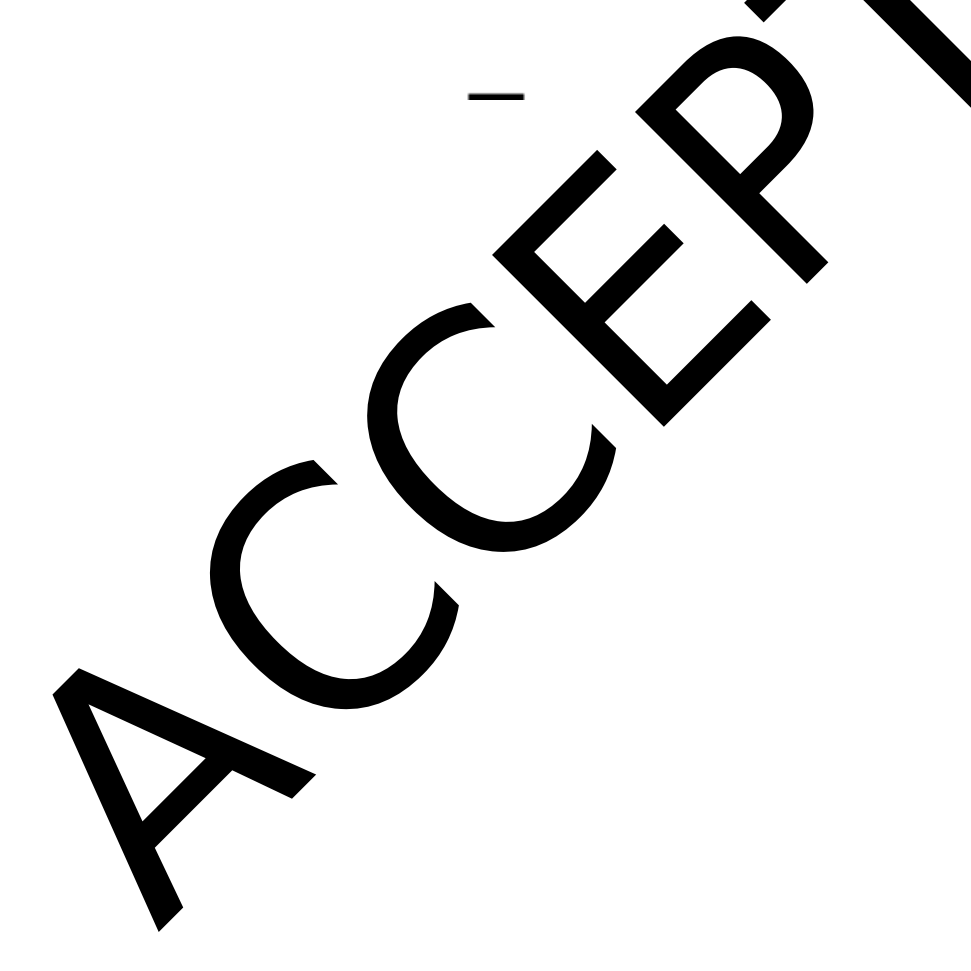

(2) 
Table 6 - Pseudo-first-order kinetics constants for MB decolorization using different photocatalysts under UVA irradiation.

\begin{tabular}{lll}
\hline Photocatalyst & $\mathbf{k}\left(\mathbf{m i n}^{-1}\right)$ & $\mathbf{R}^{2}$ \\
\hline $\mathrm{TiO}_{2} \mathrm{P} 25$ & $0.036 \pm 0.002$ & 0.997 \\
$\mathrm{P} 25-\mathrm{Hydro}$ & $0.009 \pm 0.002$ & 0.994 \\
$\mathrm{La}_{0}-\mathrm{GO}-\mathrm{TiO}_{2}$ & $0.039 \pm 0.001$ & 0.999 \\
$\mathrm{La}_{0.05}-\mathrm{GO}-\mathrm{TiO}_{2}$ & $0.029 \pm 0.002$ & 0.992 \\
$\mathrm{La}_{0.2}-\mathrm{GO}-\mathrm{TiO}_{2}$ & $0.022 \pm 0.001$ & 0.992 \\
$\mathrm{La}_{0.5}-\mathrm{GO}-\mathrm{TiO}_{2}$ & $0.014 \pm 0.000$ & 0.993 \\
$\mathrm{PLa}_{0.5}-\mathrm{TiO}_{2}$ & $0.008 \pm 0.001$ & 0.978 \\
$\mathrm{PLa}_{2}-\mathrm{TiO}_{2}$ & $0.008 \pm 0.002$ & 0.997 \\
$\mathrm{PLa}_{2}-\mathrm{TiO}_{2}$ & $0.004 \pm 0.002$ \\
\hline
\end{tabular}

The incorporation of lanthanum in $\mathrm{TiO}_{2}$, produred a strong suppression effect on the decolorization rate, which increased with hig amounts of La. Several authors have reported an enhanced photocatalytic act $\mathrm{f}_{\mathrm{MO}}$ with the addition of lanthanides and this has generally been attribute am ather factors, to a higher electronic mobility of the photogenerated char as and onsequent decrease in their recombination rate. However, the nanocomp sites prepared in this study expressed elevated rates of charge recombination as own by the PL results, which suppressed the photocatalytic activity, as exper red ba on the chemical and physical characteristics obtained. The positive effect of anides on photoactivity is generally obtained up to an optimum amount and negurect is due to the formation of recombination centers for photogenerated $e^{-}$ h $\mathrm{h}^{+}$pairs [40].

The increase in photoactivity in the visible range of the spectrum for the $\mathrm{La}^{-\mathrm{TiO}_{2}}$ composite results from the modification of the electronic structure of $\mathrm{TiO}_{2}$. However, this phenomenon is often accompanied by a marked decrease in the photoactivity of the 
catalyst in the UV region $[49,50]$. The amount of $\mathrm{La}^{3+}$ necessary to achieve the highest photoactivity under visible light irradiation may promote an excessive increase in the $\mathrm{Ti}^{3+}$ species, which acts as a photo-hole trap under UV light irradiation. Therefore, the optimum amount of $\mathrm{La}^{3+}$ is related to the amount of $\mathrm{Ti}^{3+}$ species acting as charge-carrier combination centers. This optimum amount of $\mathrm{La}^{3+}$ could be as low as $0.25 \mathrm{~mol} \%$ [49], while higher contents of $\mathrm{La}^{3+}$ would reduce the photocatalytic activity of $\mathrm{TiO}_{2}$, especially under UV irradiation. Below this low concentration, photoelectrons and photo-hole ave the slowest recombination rate and this produces the highest quantur yl Id to the photocatalytic process.

However, when GO and La are simultaneously added the suppressing effect is also noted even at very low $\mathrm{La}^{3+}$ contents $(0.05 \mathrm{~m} \%$, 5 gure 7$)$, indicating that $\mathrm{La}^{3+}$ may provide a safer and more efficient way to roarine the photocatalytic activity of $\mathrm{TiO}_{2}$ in consumer products, such as sunscreen 1 ovwers and pigments, where the total suppression is not desirable.

Although there is a shift absorption band, meaning that more photons can be absorbed in the visible region, photocatalytic activity may decrease since the addition of other sub taces (s.ch lanthanides) to $\mathrm{TiO}_{2}$ also generates structural defects on the surface on photocatalyst, such as oxygen vacancies. Depending on their quantity can act as sites of charge recombination, leading to suppression of the pheractity observed in this study. The presence of GO in the photocatalysts led to a sht herease in the photocatalytic activity. This effect can also be attributed to the righer surface area, even after heat treatment, and to the high adsorption capacity of graphene oxide, which is essential for photocatalytic reactions. Due to the antagonistic effects of La and GO, the ternary composite photocatalysts showed intermediate photocatalytic properties. The lower photocatalytic activity observed for the P25-Hydro 
sample in comparison to pristine $\mathrm{TiO}_{2} \mathrm{P} 25$ can be attributed to the marked decrease in surface area caused by the thermal treatment (Table 2).

The high visible light absorption and low PL emission, with stable photoactivity in the UV region of the $\mathrm{TiO}_{2}-\mathrm{GO}$ composites, indicates that this material may exhibit high efficiency under the full solar irradiation spectrum. Conversely, the presence of La was effective in suppressing the photocatalytic activity under UV light irradiation, wit woun altering the adsorption or charge transportation profile in the visible region of the flar spectrum. Consequently, an increase in the photocatalytic activity und r siblevight irradiation generated by the metal addition, at the concentrations stu ied, is no expected for the $\mathrm{La}-\mathrm{TiO}_{2}$ composites. This suggests that these materials excellent UV light absorbers for use in applications such as sunscree or p otocatalytic paints and in other cases where photocatalytic activity is not de cans the entire spectrum of solar light.

\section{Conclusions}

Lanthanum- $-\mathrm{TiO}_{2}-\mathrm{g}$ aphane hydrothermal metho the sults showed antagonistic effects between La and GO. Lanthanum did hfluence the absorption spectrum of $\mathrm{TiO}_{2}$, however it produced electron-bole air recombination centers, which effectively inhibited the photocatalytic activity $\leq \mathrm{Ti} d_{2}$, even at low concentrations. In addition, the rare earth inhibited particle aggmo ation and increased the thermal stability of anatase. The photocatalytic activity of $\mathrm{TiO}_{2}$ in the presence of GO slightly increases, due to the larger surface area of the composite and the high adsorption capacity of graphene oxide, which is essential for photocatalytic reactions. While most previously reported studies indicate an increase in $\mathrm{TiO}_{2}$ photoactivity following the incorporation of rare earths and carbonaceous materials, 
the results reported herein show that the incorporation of La and/or GO could be useful for the modulation and tuning of the photocatalytic activity for different commercial applications.

\section{Acknowledgments}

The authors gratefully acknowledge the Brazilian funding agencies CAPES and CNPq (Grant 405892/2013-6 and 304397/2010-5) for financial support and the aral Laboratory of Electron Microscopy (LCME) of the Federal University of sar a Catarina for the SEM and TEM analyses. To Juliana Shultz for EPR measure fents.

\section{References}

[1] J. Wen, X. Li, W. Liu, Y. Fang, J. Xie, Y. X Protalysis fundamentals and surface modification of $\mathrm{TiO}_{2}$ nanomater, V/, Crinese J. Catal. 36 (2015) 20492070. doi:10.1016/S1872-2067

[2] M.R.. HOFFMANN, ImMARYIN, W.. CHOI, D.W. BAHNEMANN, Preparation of high stab ouperhydrophobic $\mathrm{TiO}_{2}$ surfaces with completely suppressed frococatanyic activity, Chem. Rev. 95 (1995) 69-96. doi:10.102 $100033 a 004$.

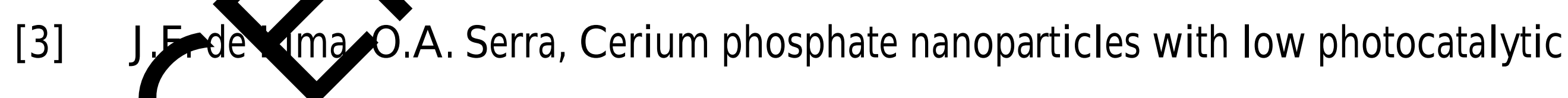
activity for UV light absorption application in photoprotection, Dye. Pigment. 97 2013) 291-296. doi:10.1016/j.dyepig.2012.12.020.

14] K. Kim, H. Ook, C. Won, M. J eong, Y. Dok, D. Chan, Preparation of highly stable superhydrophobic $\mathrm{TiO}_{2}$ surfaces with completely suppressed photocatalytic activity, Prog. Org. Coatings. 76 (2013) 596-600. doi:10.1016/j.porgcoat.2012.11.010. 
[5] U. Gesenhues, Al-doped $\mathrm{TiO}_{2}$ pigments: influence of doping on the photocatalytic degradation of alkyd resins, J. Photochem. Photobiol. A Chem. 139 (2001) 243251. doi:10.1016/S1010-6030(00)00429-9.

[6] R.A.R. Monteiro, A.M.T. Silva, J.R.M. Ângelo, G. V Silva, A.M. Mendes, R.A.R. Boaventura, et al., Photocatalytic oxidation of gaseous perchloroethylene over $\mathrm{TiO}_{2}$ based paint, J. Photochem. Photobiol. A Chem. 311 (2015) 41-52.

[7] O. Geiss, J. Barrero-Moreno, C. Cacho, D. Kotzias, Photocatalytic degrada of organic paint constituents-formation of carbonyls, Build. Environ. 8012 07 112. doi:10.1016/j.buildenv.2011.08.021.

[8] J. Virkutyte, S.R. Al-Abed, D.D. Dionysiou, Depletion proctive aluminum hydroxide coating in $\mathrm{TiO}_{2}$-based sunscreens by sw ming pool water ingredients, Chem. Eng. J. 191 (2012) 95-103. doi:10.101 (1.cos-012.02.074.

[9] X. Sun, C. Li, L. Ruan, Z. Peng, J.Zhan D. _tao, et al., Ce-doped $\mathrm{SiO}_{2} @ \mathrm{TTiO}_{2}$ nanocomposite as an effective Mhotocatalyst, J. Alloys Compd. 585 (2014) 800-804. doi:10.1810sjallcom.2013.10.034.

[10] N.R. Khalid, E. A mes, Mong, M. Ahmad, Synthesis and photocatytic properties of als ligm responsive $\mathrm{La}_{\mathrm{TiO}}$ 2-graphene composites, Appl. Surf. Sci. 263. (2072) 254-259. doi:10.1016/j.apsusc.2012.09.039.

[11] Lan, Znang, L. Wang, J. Zou, Controlling surface and interface of $\mathrm{TiO}_{2}$ to vard highly efficient photocatalysis, (2015) 1-5. doi: 101016/j.matlet.2015.06.109.

12] M. Yasmina, K. Mourad, S.H. Mohammed, C. Khaoula, Treatment heterogeneous photocatalysis; Factors influencing the photocatalytic degradation by $\mathrm{TiO}_{2}$ Energy Procedia. 50 (2014) 559-566. doi:10.1016/j.egypro.2014.06.068.

[13] T.H. Le, A.T. Bui, T.K. Le, The effect of Fe doping on the suppression of 
photocatalytic activity of $\mathrm{ZnO}$ nanopowder for the application in sunscreens, Powder Technol. 268 (2014) 173-176. doi:10.1016/j.powtec.2014.08.043.

[14] D.V. Dao, M. van den Bremt, Z. Koeller, T.K. Le, Effect of metal ion doping on the optical properties and the deactivation of photocatalytic activity of $\mathrm{ZnO}$ nanopowder for application in sunscreens, Powder Technol. 288 (2016) 366-370. doi:10.1016/j.powtec.2015.11.030.

[15] U. Diebold, The surface science of titanium dioxide, Surface Science Rapo 48 (2003) 53-229.

[16] M.A. Henderson, A surface science perspective on $\mathrm{TiO}_{2}$ phot catalysis, Surf. Sci. Rep. 66 (2011) 185-297. doi:10.1016/j.surfrep.2011.01.

[17] R. Marschall, L. Wang, Non-metal doping of trans ion n etal oxides for visiblelight photocatalysis, Catal. Toda 25 (2014) 111-135. doi:10.1016/j.cattod.2013.10.088.

[18] B. Ohtani, K. Iwai, H. Kon Matsuura, Y. Kera, S. Nishimoto, Titanium(IV) oxide photg atanst of ultra-high activity for selective $\mathrm{N}$-cyclization of an amino acid in queous spensions, Chem. Phys. Lett. 242 (1995) 315-319. doi:10.1016/Q0 2614/S)00740-U.

[19] P.K.J. RRelson, J.M.C. Robertson, D.W. Bahnemann, Removal of minoo anigns and their chemical metabolites from water using semiconductor plocolalysis, J. Hazard. Mater. 211-212 (2012) 161-171. 10.1016/j.jhazmat.2011.11.058.

20] X. Lan, L. Wang, B. Zhang, B. Tian, J. Zhang, Preparation of lanthanum and boron co-doped $\mathrm{TiO}_{2}$ by modified sol-gel method and study their photocatalytic activity, Catal. Today. 224 (2014) 163-170. doi:10.1016/j.cattod.2013.10.062.

[21] Y. Chen, K. Liu, Preparation of granulated N-doped $\mathrm{TiO}_{2} /$ diatomite composite 
and its applications of visible light degradation and disinfection, Powder Technol. 303 (2016) 176-191. doi:10.1016/j.powtec.2016.09.038.

[22] J. Li, X. Yang, X. Yu, L. Xu, W. Kang, W. Yan, et al., Rare earth oxide-doped titania nanocomposites with enhanced photocatalytic activity towards the degradation of partially hydrolysis polyacrylamide, Appl. Surf. Sci. 255 (2009) 3731-3738. doi:10.1016/j.apsusc.2008.10.029.

[23] F. Wu, W. Liu, J. Qiu, J. Li, W. Zhou, Y. Fang, et al., Enhanced photocat dic degradation and adsorption of methylene blue via $\mathrm{TiO}_{2}$ nanocryst 5 gooned on graphene-like bamboo charcoal, Appl. Surf. Sci (2015). doi:10.1016/j.apsusc.2015.08.161.

[24] N.P. Radhika, R. Selvin, R. Kakkar, A. Unan, Rece tt advances in nanophotocatalysts for organic synthesis, J. Chem. (2016). doi:10.1016/j.arabjc.2016.07.007.

[25] T.-D. Nguyen-Phan, V.H. Phan S.in, H.-D. Pham, S. Kim, J.S. Chung, et al., The role of graphene content on the adsorption-enhanced photocatalysis of titanium dioxide Jraphe composites, Chem. Eng. J. 170 (2011) 226 232. doi:10.10 coj.211.03.060.

[26] X. Li, R. SYen, S. Ma, X. Chen, J. Xie, Graphene-based heterojunction Appl. Surf. Sci. $430 \quad$ (2018) 53-107. 10 16/j.apsusc. 2017.08.194.

[2 Li, J. Yu, S. Wageh, A.A. Al-Ghamdi, J. Xie, Graphene in Photocatalysis: A Review, Small. 12 (2016) 6640-6696. doi:10.1002/smll.201600382.

[28] Y. YU, G. CHEN, Y. ZHOU, Z. HAN, Recent advances in rare-earth elements modification of inorganic semiconductor-based photocatalysts for efficient solar energy conversion: A review, J. Rare Earths. 33 (2015) 453-462. 
doi:10.1016/S1002-0721(14)60440-3.

[29] L. Yu, X. Yang, J. He, Y. He, D. Wang, Synthesis of magnetically separable N, La-doped $\mathrm{TiO}_{2}$ with enhanced photocatalytic activity, Sep. Purif. Technol. 144 (2015) 107-113. doi:10.1016/j.seppur.2015.02.007.

[30] Y. Zhang, H. Xu, Y. Xu, H. Zhang, Y. Wang, The effect of lanthanide on the degradation of RB in nanocrystalline $\mathrm{Ln} / \mathrm{TiO}_{2}$ aqueous solution, J. Photock $\mathrm{m}$. Photobiol. A Chem. 170 (2005) 279-285. doi:10.1016/j.jphotochem.2004.0 01.

[31] V.Z. Baldissarelli, T. de Souza, L. Andrade, L.F.C. de Oliveira, osé, de F.P.M. Moreira, Preparation and photocatalytic activity of TiQ2 exfoliated graphite oxide composite using an ecofriendly graphite anon method, Appl. Surf. Sci. 359 (2015) 868-874. doi:10.1016/j.apsus 2015) 0.199.

[32] Z.M. El-Bahy, A.A. Ismail, R.M. Mohamed, Nmoment of titania by doping rare earth for photodegradation of organ 8 ye (Direct Blue)., J. Hazard. Mater. 166 (2009) 138-43. doi:10.1016 mat.2008.11.022.

[33] V. Štengl, S. Bakardjiev Murafă, Preparation and photocatalytic activity of rare earth doped Ti 2 pandicles, Mater. Chem. Phys. 114 (2009) 217-226. doi:10.1016/j hat chemprys.2008.09.025.

[34] Y. Min K. Y lang, W. Zhao, F. Zheng, Y. Chen, Y. Zhang, Enhanced chemical

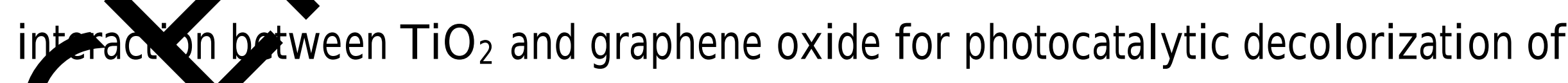
mothylhe blue, Chem. Eng. J. 193-194 (2012) 203-210. 10.1016/j.cej.2012.04.047.

15] C. Liu, L. Zhang, R. Liu, Z. Gao, X. Yang, Z. Tu, et al., Hydrothermal synthesis of $\mathrm{N}$-doped $\mathrm{TiO}_{2}$ nanowires and $\mathrm{N}$-doped graphene heterostructures with enhanced photocatalytic properties, J. Alloys Compd. 656 (2016) 24-32. doi:10.1016/j.jallcom.2015.09.211. 
[36] J. Suave, S.M. Amorim, J. Ângelo, L. Andrade, A. Mendes, R.F.P.M. Moreira, $\mathrm{TiO}_{2} /$ reduced graphene oxide composites for photocatalytic degradation in aqueous and gaseous medium, J. Photochem. Photobiol. A Chem. 348 (2017) $326-$ 336. doi:10.1016/j.jphotochem.2017.08.064.

[37] V. Binas, D. Venieri, D. Kotzias, G. Kiriakidis, Modi fi ed $\mathrm{TiO}_{2}$ based photocatalysts for improved air and health quality, J Mater. 3 (2017) 316. doi:10.1016/j.jmat.2016.11.002.

[38] Y. Ao, L. Xu, P. Wang, C. Wang, J. Hou, J. Qian, et al., Grapher an LTio 2 comodified flower-like $\mathrm{Bi}_{2} \mathrm{O}_{2} \mathrm{CO}_{3}$ : A novel multi-heterojunctio photocazalyst with enhanced photocatalytic activity, Appl. Surf. Sai (2015) 411-418. doi:10.1016/j.apsusc.2015.07.027.

[39] C. P. Kumar, N. O. Gopal, T. C. Wang, M. S. W ng, Ac. Ke, EPR Investigation of $\mathrm{TiO}_{2}$ Nanoparticles with Temperature-Lepentuent Properties, The Journal of Physical Chemistry B, 110 (2006 -22 -529, doi: 10.1021/jp057053t.

[40] O. I. Micic, Y. Zhang, K. Oromack, A. D. Trifunac, M. C. Thurnauer. Trapped Holes on $\mathrm{TiO}_{2}$ Colle as Stua by Electron Paramagnetic Resonance, The Journal of Physical Ch matry, 9 (1993) 7277-7283. doi: 10.1021/j100130a026

[41] S. Silvestri, 22poganicz, J. Schultz, A. S. Mangrich, D. Hotza,D. E. García, J. A. Labminc. Doped and undoped anatase-based plates obtained from paper templates fo vot catalytic oxidation of NOx, Ceramics International, 42 (2016) 12074283. doi: 10.1016/j.ceramint.2016.04.137

42] J. Hongquan, L. Yanduo, L. Jingshen, W. Haiyan, W. Synergetic effects of lanthanum, nitrogen and phosphorus tri-doping on visiblelight photoactivity of $\mathrm{TiO}_{2}$ fabricated by microwave-hydrothermal process, J ournal of Rare Earths, 34 (2016) 604-613. doi: 10.1016/S1002-0721(16)60068-6. 
[43] A. J. Maira,K. L. Yeung, J. Soria, J. M. Coronad, C. Belver, C. Y. Lee, V. Augugliaro, Gas-phase photo-oxidation of toluene using nanometer-size $\mathrm{TiO}_{2}$ catalysts, Applied Catalysis B: Environmental, 29 (2001) 327-336, doi: $10.1016 / 50926-3373(00) 00211-3$.

[44] U. Alam, M. Fleisch, I. Kretschmer, D. Bahnemann, M. Muneer, M. One-step hydrothermal synthesis of $\mathrm{Bi}^{-\mathrm{TiO}_{2}}$ nanotube/graphene composites: An efficent photocatalyst for spectacular degradation of organic pollutants under viciblaght irradiation, Applied Catalysis B: Environmental, 218 (2017) 55 . 169, doi: 10.1016/j.apcatb.2017.06.016.

[45] E. A. Konstantinova, V. Y. Gayvoronskiy, V. Y. Timos o, P. K. Kashkarov, Study of Spin Centers in Nanocrystalline Titanium wioxide with a High Degree of Photocatalytic Activity, Semiconductors, 44 2010) 1059-1063, doi: $10.1134 / S 106378261008018 X$

[46] C. P. Sibu, S. R. Kumar, P. Mukb K.G. K. Warrier, Structural Modifications and Associated Properties Quthan Oxide Doped Sol-Gel Nanosized Titanium Oxide, Chemistry of laterla 14 (2002) 2876-2881, doi: 10.1021/cm010966p.

[47] D. Xu, L. Fen, A. M, Characterizations of lanthanum trivalent ions/TiO 2 nanopoyde atalysis prepared by plasma spray, Journal of Colloid and Interface Scince, 29/2009) 395-403, doi: 10.1016/j.jcis.2008.09.048.

[48 K. Plida, N. Sahu, Visible light induced photocatalytic activity of rare earth tiuania nanocomposites, J. Mol. Catal. A Chem. 287 (2008) 151-158. doi:10.1016/j.molcata.2008.02.028.

[49] S. Yuan, Q. Sheng, J. Zhang, F. Chen, Synthesis of $\mathrm{La}^{3+}$ doped mesoporous titania with highly crystallized walls, Microporous Mesoporous Mater. 79 (2005) 93-99. doi:10.1016/j.micromeso.2004.10.028. 
[50] L. Elsellami, H. Lachheb, A. Houas, Synthesis, characterization and photocatalytic activity of Li-, Cd-, and La-doped $\mathrm{TiO}_{2}$, Mater. Sci. Semicond. Process. 36 (2015) 103-114. doi:10.1016/j.mssp.2015.03.032.

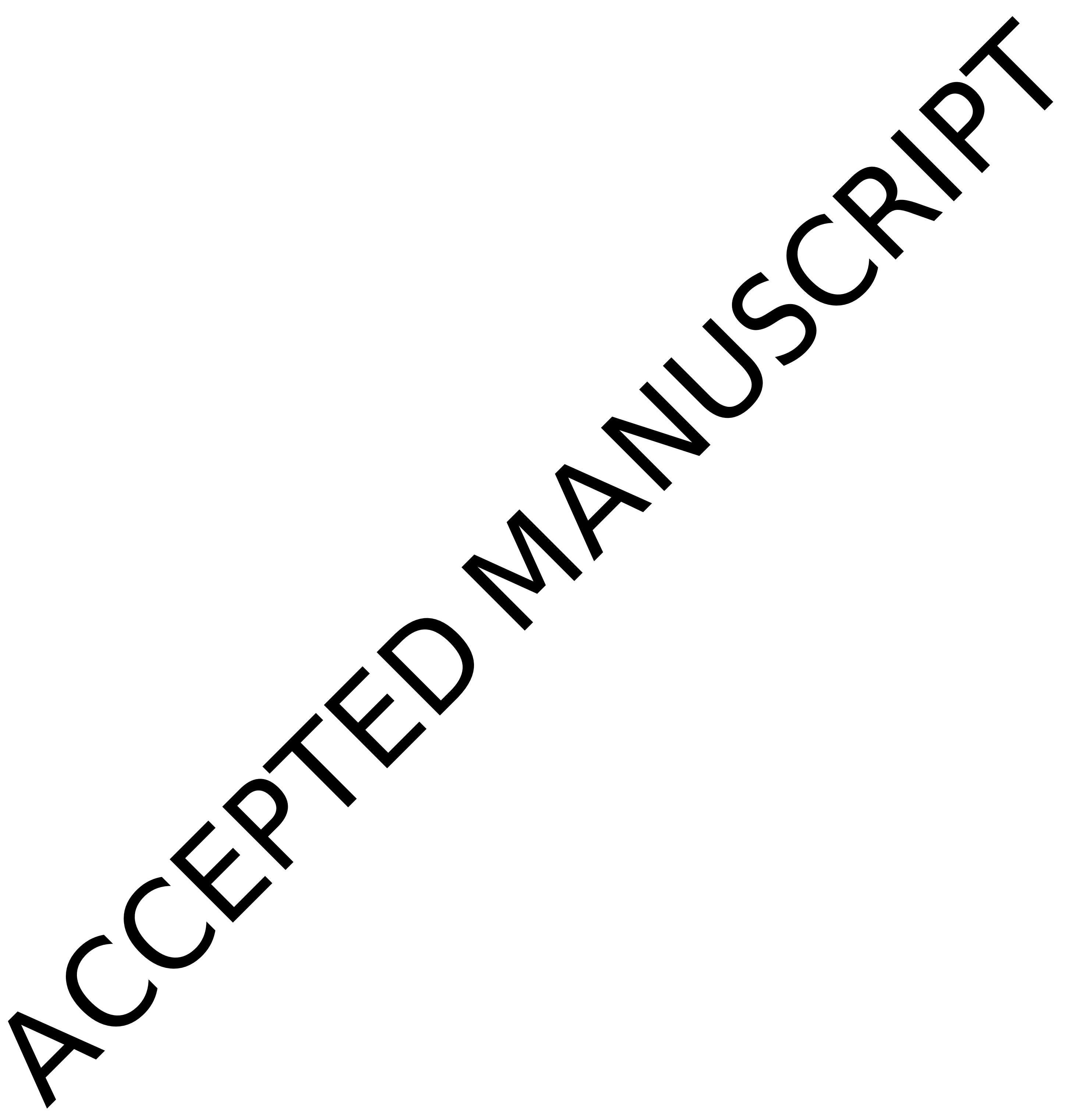

